\title{
Inactivation of oral biofilms using visible light and water-filtered infrared A radiation and indocyanine green
}

\author{
Thomas Burchard', Lamprini Karygianni², Elmar Hellwig33, Marie Follo4 ${ }^{4}$ Thomas Wrbas ${ }^{3}$, \\ Annette Wittmer ${ }^{5}$, Kirstin Vach ${ }^{6}$ \& Ali Al-Ahmad*,3 \\ ${ }^{1}$ Department of Prosthetic Dentistry, Center for Dental Medicine, Medical Center, University of Freiburg, Faculty of Medicine, \\ University of Freiburg, Freiburg, Germany \\ ${ }^{2}$ Clinic of Preventive Dentistry, Periodontology \& Cariology, Center of Dental Medicine, University of Zurich, Switzerland \\ ${ }^{3}$ Department of Operative Dentistry \& Periodontology, Center for Dental Medicine, Medical Center, University of Freiburg, Faculty \\ of Medicine, University of Freiburg, Freiburg, Germany \\ ${ }^{4}$ Department of Hematology, Oncology \& Stem Cell Transplantation, Medical Center, University of Freiburg, Faculty of Medicine, \\ University of Freiburg, Freiburg, Germany \\ ${ }^{5}$ Department of Hygiene \& Microbiology, Medical Center, University of Freiburg, Faculty of Medicine, University of Freiburg, \\ Freiburg, Germany \\ ${ }^{6}$ Department of Medical Biometry \& Statistics, Faculty of Medicine, University of Freiburg, Germany \\ *Author for correspondence: Tel.: +49 7612704 8940; Fax: +49 7612704 7620; ali.al-ahmad@uniklinik-freiburg.de
}

Aim: To investigate the antimicrobial photodynamic therapy (aPDT) of visible light and water-filtered infrared $A$ radiation in combination with indocyanine green (ICG) on planktonic oral microorganisms as well as on oral biofilm. Methods: The irradiation was conducted for 5 min in combination with ICG. Treatment with chlorhexidine served as a positive control. The number of colony forming units and bacterial vitality were quantified. Results: All tested bacterial strains and salivary bacteria were killed at a level of $3 \log _{10}$. The colony forming units of the initial mature oral biofilms were strongly reduced. The high bactericidal effect of aPDT was confirmed by live/dead staining. Conclusion: The aPDT using visible light and water-filtered infrared A radiation and ICG has the potential to treat periodontitis and peri-implantitis.

First draft submitted: 19 October 2018; Accepted for publication: 9 May 2019; Published online: 1 August 2019

Keywords: antimicrobial photodynamic therapy $\bullet$ aPDT $\bullet$ ICG $\bullet$ indocyanine green $\bullet$ oral biofilm $\bullet$ VIS+WIRA $\bullet$ visible light and water-filtered infrared $\mathrm{A}$

Photoactivated disinfection with toluidine blue (TB) and methylene blue (MB) is currently used in dentistry to reduce the number of microorganisms in root canals, cavities and the periodontium [1-5]. Conventional mechanical treatments are unable to completely remove biofilms due to poor accessibility [6-8]. This technique was investigated because, in contrast to many chemicals used for disinfection for example chlorhexidine (CHX), this method is able to completely eradicate nonaccessible bacteria in root canals or in cavities within the tooth. The reason for this is due to the morphology of dentin and root cement. This kind of morphology offers niches for microorganisms into which biocompatible chemicals cannot penetrate [9-11]. This often requires additional antibiotic therapy, which however, should be used only rarely and with care, especially with regard to the rise in antibiotic resistance.

Due to unfavorable outcomes correlating with the use of established oral biofilm treatments, the introduction of antimicrobial photodynamic therapy (aPDT) is considered as a noninvasive, biofilm-targeted and affordable photochemical technique against polymicrobial oral infections, especially as an alternative to antibiotic therapy [12,13]. The aPDT cannot only be used against current dental infections but also as a photodynamic disinfection during follow-up care and as prevention measure, for example, in the field of oral surgery and implantology, to sterilize the bone cavity [14,15].

Upon illumination, the antimicrobial effect of aPDT occurs as an oxidative burst and damages biomolecules as well as other cellular structures and in a nonselective way. The aPDT necessitates the presence of three components: a nontoxic photosensitizer, molecular oxygen and visible light of a specific wavelength [2]. 
The aPDT can be applied either with broadband halogen lamps or light emitting diodes (LED) as light sources [1619]. Nevertheless, the limited emission wavelength spectrum associated with cheap LED devices and broadband halogen lamps results in tissue overheating [1].

A promising alternative is the previously described combination of a wide band light source with visible light (VIS) wavelengths and water-filtered infrared A (wIRA) wavelengths [20]. The benefits of combining VIS with wIRA include increasing in situ temperature without thermal stress on the external tissue layers. It also increases tissue oxygen partial pressure and improves tissue perfusion, promoting tissue regeneration and pain relief [21]. The absorption spectrum of photosensitizers could be modified (shifted) after application in situ, in other words, in the oral cavity. This shift should be compensated by a broadband light source like the combination of VIS and wIRA. Furthermore, wIRA is a special form of infrared radiation with high subcutaneous tissue penetration at low thermal surface load, allowing a significantly higher energy input into the tissue and showing both thermal and temperature-dependent, as well as nonthermal and temperature-independent effects [22,23].

In recent studies, high antimicrobial effects of aPDT using VIS and wIRA (VIS+wIRA) in combination with photosensitizers like MB, TB and chlorine e6 (Ce6) against planktonic and adherent microorganisms have been established [20,24]. These previous studies have shown that aPDT using VIS+wIRA shows great potential as an adjunctive therapy for peri-implantitis and periodontitis, as both the initial and mature oral biofilm have to a large extent been eradicated. Photosensitizers, which are clinically approved, are required to conduct clinical trials. While Ce6 is promising, it has not to date been approved for in situ use in the oral cavity.

Unlike other photosensitizers indocyanine green (ICG), a photosensitizer belonging to the polymethine group has been approved by US FDA [25]. ICG is a water-soluble anionic tricarbocyanine dye, which is used not only for bioimaging but also because of its near infrared absorption and its fluorescence emission properties, also as a cytotoxic photosensitizer for aPDT, when combined with light at wavelengths between 800 and $830 \mathrm{~nm}$ [26]. As a potential advantage over other photosensitizers, it should be noted that ICG is metabolized in the liver and has low toxicity as it is not absorbed by the intestinal mucous membrane [26]. After light absorption, the ICG molecule can follow three main pathways to deactivate its excited singlet state. The absorbed energy can be released as fluorescence emission between 750 and $950 \mathrm{~nm}$, depending on solvent and dye concentrations. In addition, a part of the energy can be transferred to an ICG triplet state, which generates reactive oxygen species (ROS), or the energy can be transformed into heat within the ICG molecule through internal conversion [27]. In contrast to $\mathrm{MB}, \mathrm{TB}$ and Ce6, most of the absorbed light is transformed into heat so that the effect of ICG is described as photothermal and photo-oxidative [28-30]. Thereby, the depth of penetration is increased compared with the other established photosensitizers.

However, most publications relating aPDT with ICG used diode lasers and are restricted to examinations of planktonic bacteria [31,32] except for a few publications examining biofilm formation [33-37].

Promising results by Omar et al. [38] using aPDT with ICG as a photosensitizer and a near-infrared laser $(808 \mathrm{~nm})$ as a light source showed a high reduction (up to 99\%) of Gram-positive (Streptococcus pyogenes, Staphylococcus aureus) and Gram-negative (Pseudomonas aeruginosa) bacteria. Additionally, significant reductions in the biofilm (up to 67\% for Streptococcus mutans and about $43 \%$ for Enterococcus faecalis, respectively) using aPDT with ICG and a diode laser as the light source were reported [33,34]. Until now, the suitability of this photosensitizer in combination with VIS+wIRA and its beneficial effects compared with other light sources used to kill oral or initially adherent germs has not been investigated.

In the present study, the antimicrobial effect of photosensitization on pure microorganisms and total salivary flora, as well as on initial and mature oral biofilms, were investigated in vitro using ICG as a photosensitizer in combination with VIS+wIRA. For this purpose, pure planktonic cultures of five common oral bacteria (S. mutans, E. faecalis, Eikenella corrodens, Fusobacterium nucleatum and Veillonella parvula) were grown in vitro. In addition, initial and mature intact oral biofilms were grown on BES within the oral cavity for either $2 \mathrm{~h}$ or 3 days, respectively. The planktonic bacterial cultures, total salivary bacteria, as well as oral biofilms were then treated with aPDT using VIS+wIRA in combination with ICG. The surviving bacteria from the treated initial and mature oral biofilms were determined as colony forming units (CFU), and the isolated species were identified. Additionally, for visualization and quantification live/dead staining was performed. The findings are a prerequisite for further clinical studies and essential to get knowledge about the possibility of using ICG as a photosensitizer with VIS+wIRA as an alternative to typical antimicrobial treatment methods in the field of dentistry. 


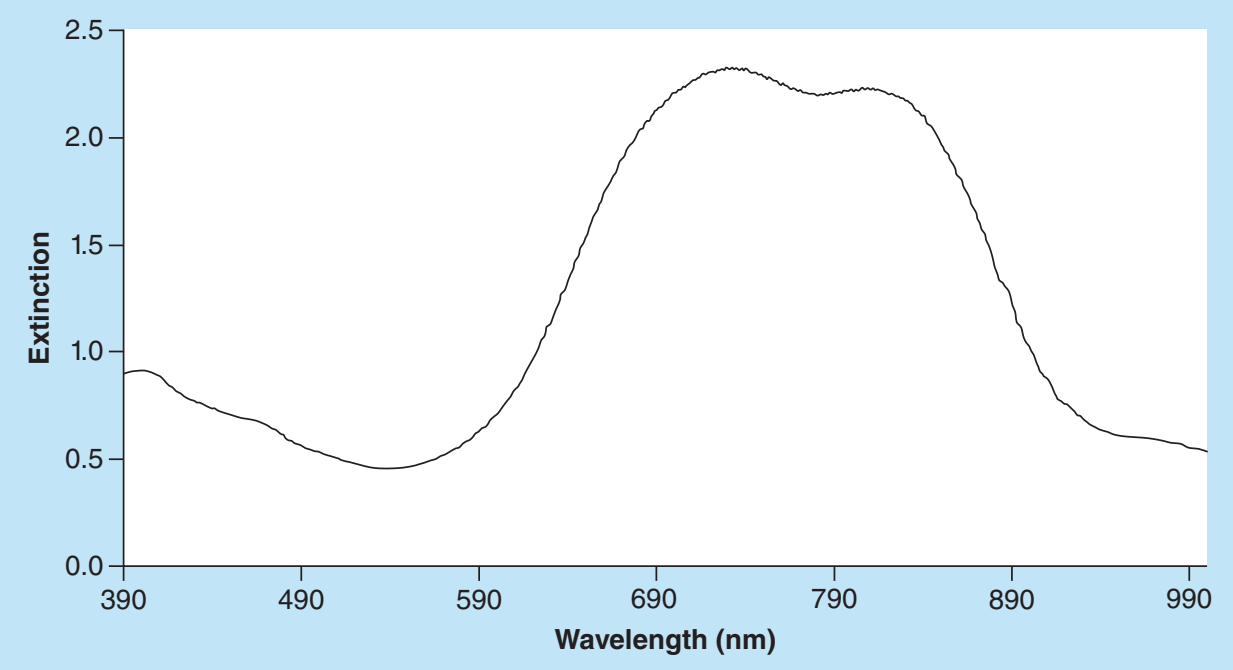

Figure 1. Absorption spectrum of the indocyanine green in water. The concentration of the dye was $300 \mu \mathrm{g} / \mathrm{ml}$. The measurement of the spectrum was conducted a Tecan Infinite 200 reader (Tecan, Crailsheim, Germany).

\section{Materials \& methods}

\section{Light source \& photosensitizer}

In this study, a broad-band VIS+wIRA radiator (Hydrosun 750FS, Hydrosun Medizintechnik, Müllheim, Germany) with a $7 \mathrm{~mm}$ water cuvette was used as previously described [20,24,39]. Instead of the usual filter, a different orange filter, BTE31 - with more than twice the effective integral irradiance compared with the absorption spectrum of protoporphyrin IX - was used. Protoporphyrin IX is also included in bacterial cells and could improve the outcome of photodynamic inactivation. This has been now added to the introduction section. The continuous water-filtered spectrum with local minima at 970, 1200 and $1430 \mathrm{~nm}$, ranged between 570 and $1400 \mathrm{~nm}$ [40]. The following absorption bands of IRA were removed by the water filter: 944, 1180 and $1380 \mathrm{~nm}$. This emission spectrum, which has been depicted extensively in the literature [41,42], covers the broad absorbance spectrum of ICG $(600-840 \mathrm{~nm})$ which is depicted in Figure 1. The aPDT was applied for $5 \mathrm{~min}$, including approximately $48 \mathrm{~mW} / \mathrm{cm}^{2}$ VIS and $152 \mathrm{~mW} / \mathrm{cm}^{2}$ wIRA, a total of $200 \mathrm{~mW} / \mathrm{cm}^{2}$ VIS +wIRA.

The photosensitizer used was ICG (perio green ${ }^{\circledR}$, elexxion, Singen, Germany). Due to the contraindication of iodine allergy listed by the manufacturer, the presence of about $5 \%$ iodide is assumed, the sole purpose of which is to improve solubility [11]. ICG solutions were prepared in water for injection at different concentrations of $50 \mu \mathrm{g} / \mathrm{ml} \mathrm{up}$ to $500 \mu \mathrm{g} / \mathrm{ml}$. The ICG solution was stored in the dark for no longer than $4 \mathrm{~h}$ before use to prevent any light-induced photochemical attenuation. The optical absorption spectrum of ICG revealed maximum absorption peaks in the region from $800-830 \mathrm{~nm}$ [26]. The emission spectrum of this light source covers the entire absorbance spectrum of ICG $(600-840 \mathrm{~nm})$ which can also vary depending on the application site in the oral cavity. Furthermore, the broad emission spectrum enables efficient activation of the photosensitizer. Irradiation with VIS+wIRA activates ICG without causing an overheating of the human soft tissue. This has been now added to the depiction of the used dye. The absorption spectrum of the used ICG in water is depicted in Figure 1.

\section{Bacterial strains}

Clinical isolates of E. faecalis T9 and S. mutans DSM 20523 were cultivated on Columbia blood agar (CBA) plates, as well as E. corrodens FB69/36-26 on yeast-cysteine blood agar (HCB) plates at $37^{\circ} \mathrm{C}$ in an aerobic atmosphere with $5 \% \mathrm{CO}_{2}$. The bacteria were derived from long-term storage at $-80^{\circ} \mathrm{C}$ in brain heart infusion medium containing $15 \%$ (v/v) glycerol as described earlier [43]. Further isolates of F. nucleatum ATCC 25586 and V. parvula DSM 2008 were cultivated on HCB plates under anaerobic conditions (anaerobic jars, GENbox anaer; Biomerieux, Marcyl'Etoile, France). Long-term storage of these anaerobic bacteria was performed at $-80^{\circ} \mathrm{C}$ in basal glucose phosphate growth medium containing 15\% (v/v) glycerol as described elsewhere [43]. 


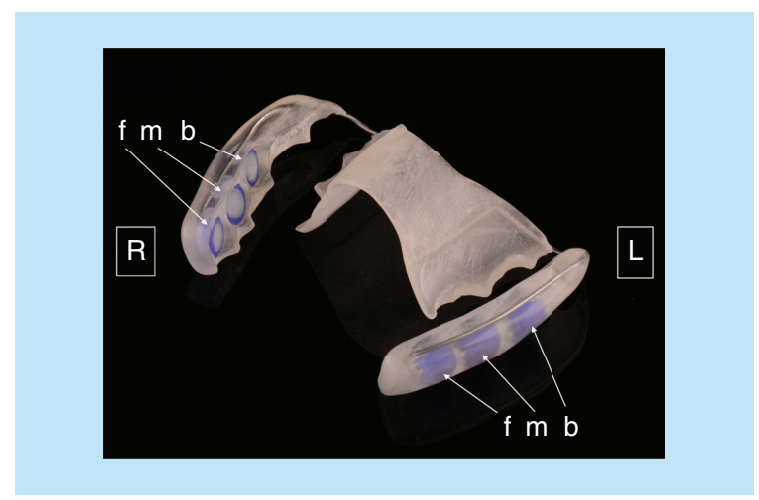

Figure 2. Individual acrylic splints with six enamel slabs attached to different locations. The slabs were placed in the front, in the middle and in the back on both sides, right and left. All sides of the slabs except the enamel surface were covered with silicone and embedded in the appliance.

b: Back; f: Front; L: Left; m: Middle; R: Right.

Overnight cultures of aerobic bacterial strains were prepared in tryptic soy broth (TSB, Merck, Darmstadt, Germany) and in gas chromatography (Hewlett Packard, VA, USA) bouillon for anaerobic bacterial strains. All bacterial strains were kindly provided by the Institute of Medical Microbiology and Hygiene of the Albert Ludwigs University (Freiburg, Germany). In addition, unstimulated human saliva from three healthy volunteers, which had not used antibacterial mouth rinses or any antibiotics in 3 months prior to the start of the study, was investigated. The saliva and $8 \mathrm{ml}$ cell suspensions of each organism were centrifuged at $4000 \mathrm{~g}$ for $10 \mathrm{~min}$. Finally, after discarding the supernatant, $8 \mathrm{ml} 0.9 \%$ saline solution $\mathrm{NaCl}$ was added.

\section{Selection of study participants \& test specimens}

The study protocol was reviewed and approved by the local ethics committee (no. 502/13). An explanation and declaration of consent were signed by all participants in advance and are available in writing.

By a preliminary clinical examination of the oral cavity, three healthy volunteers were selected to participate in the study. The exclusion criteria were defined as follows: systemic disease, salivary glands disorders, caries or periodontal disease, pregnancy or lactation, smoking, use local antimicrobial agents such as CHX of antibiotics within the last 3 months. All participants had optimal oral hygiene prior to the study.

For the preparation of the test specimens, anterior teeth of 2 year old, BSE (spongiform encephalopathy) free cattle were used, which had been slaughtered at a slaughterhouse in Freiburg, Germany. In order to prepare cylinders (diameter: $5 \mathrm{~mm}$, surface area: $19.63 \mathrm{~mm}^{2}$, height: $1 \mathrm{~mm}$ ), as previously described [44], only the buccal surface of the teeth was used. Subsequently, the bovine enamel slabs (BES) were polished by using wet sandpaper in a grinding machine (Knuth-Rotor-3, Struers; Willich, Germany) in decreasing order of grain size (250-4000 grit). The BES were then controlled under a light microscope (Wild M3Z, Leica) and were finally disinfected. The BES disinfection protocol involved ultrasonication in $\mathrm{NaOCl}(3 \%)$ for 3 min to remove the superficial smear layer, air-drying and ultrasonication for $3 \mathrm{~min}$ in 70\% ethanol. Finally, the BES were ultrasonicated again for $10 \mathrm{~min}$ in double-distilled water and stored in distilled water for $24 \mathrm{~h}$ to hydrate prior to the assays [45].

Individual maxillary acrylic devices were prepared for each volunteer in the study and six BES were attached approximately using an A-silicon compound (Panasil initial contact X-Light, Kettenbach; Eschenburg, Germany) [46]. The lateral BES margins were covered with silicon to ensure the exposure solely of the BES surfaces in the oral cavity (Figure 2). With the help of the acrylic appliances, the BES were placed at the interdental area between upper premolars and molars to avoid disturbing movements of the tongue or cheek. Each participant carried $12 \mathrm{BES}$ within the given time periods ( $2 \mathrm{~h}, 3$ days). To avoid any biofilm disruption, the maxillary splint was not brushed. During meals and the performance of oral hygiene, the BES-containing splints were removed and deposited in sterile $0.9 \% \mathrm{NaCl}$. The BES were removed from the oral cavity and rinsed with sterile $0.9 \%$ saline solution for 30 sec after the given test periods of $2 \mathrm{~h}$ and 3 days, respectively. The silicon was detached from the samples by using sterile tweezers.

\section{Antimicrobial photodynamic therapy of bacterial strains \& biofilm samples}

Bacterial suspension with different concentrations of ICG $(50-500 \mu \mathrm{g} / \mathrm{ml})$ were prepared in duplicate in two multiwell plates (24-well plate, Greiner Bio-One; Frickenhausen, Germany), with samples containing $1 \mathrm{ml}$. Negative controls were bacterial strains with $0.9 \% \mathrm{NaCl}$, while positive controls were bacterial strains with $0.2 \% \mathrm{CHX}$. Prior to irradiation, the multiwell plates were initially incubated for $2 \mathrm{~min}$ in the dark. Irradiation was then applied 


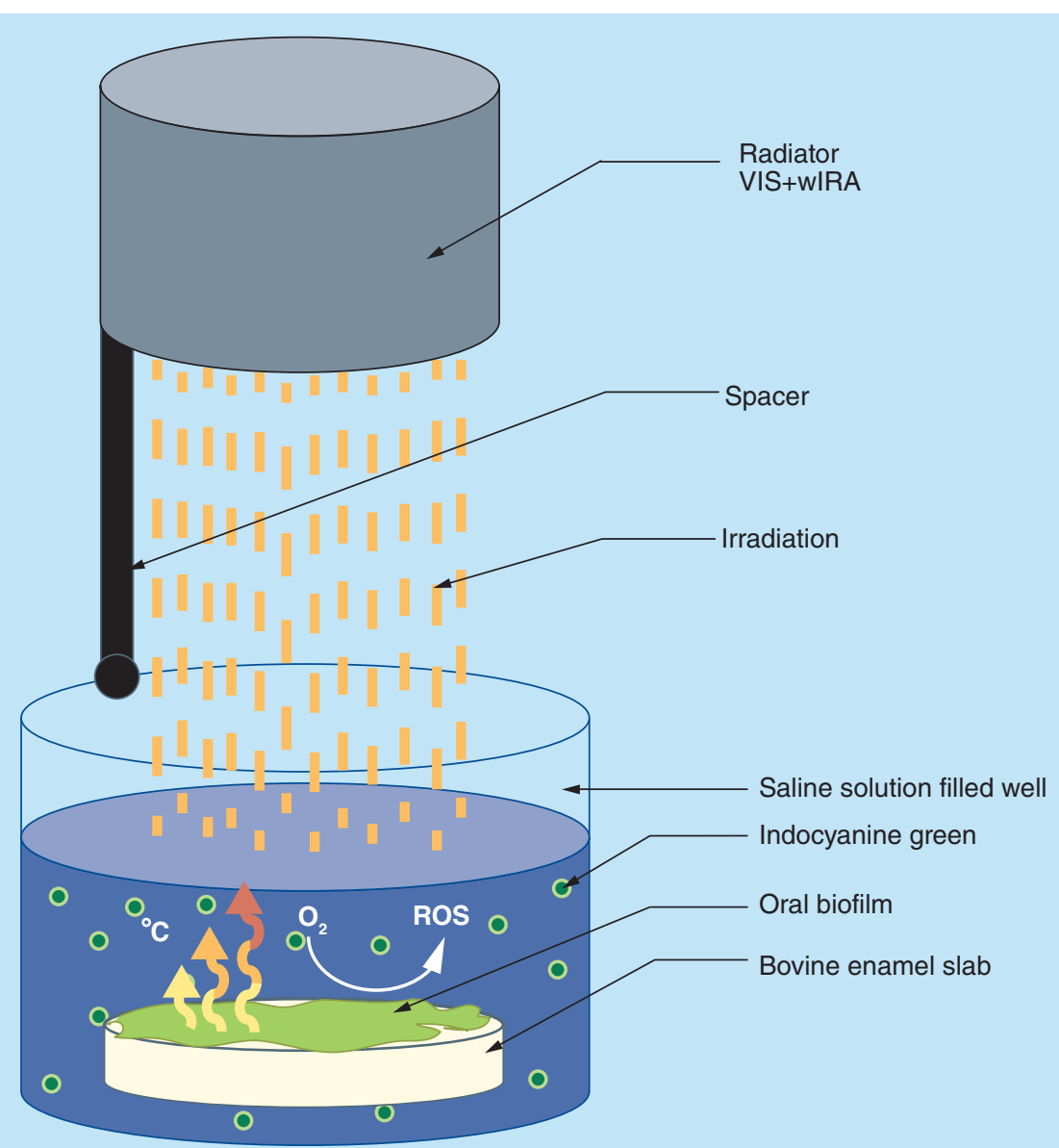

Figure 3. Schematic representation antimicrobial photodynamic therapy with visible light plus water-filtered infrared A. The tested photosensitizer indocyanine green reached an excited singlet state after the application of a broadband VIS + wIRA radiator with a water-filtered spectrum ranging between 570 and $1400 \mathrm{~nm}$. The excited photosensitizer interacted with oxygen $\left(\mathrm{O}_{2}\right)$, resulting to the release of thermal energy and various reactive oxygen species.

VIS + wIRA: Visible light and water-filtered infrared A radiation.

to one of the multiwell plates at $37^{\circ} \mathrm{C}$ for $5 \mathrm{~min}$ in a water bath while the other plate was further stored in the dark. Each of the experiments was conducted twice. After VIS+wIRA irradiation of S. mutans, E. faecalis and E. corrodens, a dilution series of each of the treated bacterial solutions was prepared and each dilution was plated on $\mathrm{CBA}$ - or $\mathrm{HCB}$ plates followed by cultivation at $37^{\circ} \mathrm{C}$ in an aerobic atmosphere of $5 \% \mathrm{CO}_{2}$. For F. nucleatum and $V$. parvula $\mathrm{HCB}$ plates were used to determine the surviving CFU under anaerobic conditions (anaerobic jars, GENbox anaer, Biomerieux). The procedure as described above applies in principle for the biofilm samples and the human saliva samples. Two out of a total of six specimens were used as controls, one plate served as a negative control treated with $\mathrm{NaCl}$ and one plate as a positive control treated with $\mathrm{CHX}$. The remaining samples were treated using aPDT with $300 \mu \mathrm{g} / \mathrm{ml}$ or $450 \mu \mathrm{g} / \mathrm{ml} \mathrm{ICG} \mathrm{ex} \mathrm{vivo,} \mathrm{respectively.} \mathrm{For} \mathrm{the} \mathrm{application} \mathrm{of} \mathrm{aPDT,} \mathrm{the}$ $\mathrm{BES}$ and their adherent biofilms were transferred into a multiwell plate with $1 \mathrm{ml} 0.9 \% \mathrm{NaCl}$, incubated and then irradiated in the same way as described for the bacterial strains (Figure 3). Afterward, the surviving bacteria were plated on $\mathrm{CBA}$ or HCB plates and incubated under both aerobic and anaerobic conditions as described above. Quantification of the microorganisms by determination of the CFU followed. The latter is assumed to have a toxic effect on initially adherent microorganisms and resistant structures, such as oral biofilms. Any heat effect due to radiation from the light source can be excluded by the use of VIS + wIRA. 


\section{Live/dead staining \& confocal laser scanning microscopy}

To quantify the live and dead bacteria within the biofilm, additional BES adherent biofilm samples from a second cycle were obtained for each time period and visualized after appropriate treatment using live/dead staining. For the vital staining and CLSM assay, SYTO 9 and propidium iodide (PI) were used for fluorescent staining (Live/Dead BacLight Bacterial Viability Kit, Life Technologies; Darmstadt, Germany) [47]. The green fluorescent stain can penetrate both intact and damaged bacterial membranes, the red fluorescent staining is only able to penetrate the latter. Therefore, viable bacteria in the CLSM have green fluorescence whereas dead bacteria have red fluorescence. For biofilm staining, the BES were transferred to a multiwell plate, which was filled with $1 \mathrm{ml}$ of SYTO 9/PI in $0.9 \% \mathrm{NaCl}$ per well and incubated for $10 \mathrm{~min}$ at room temperature in the dark. For this purpose, the fluorescent agents were previously diluted with $0.9 \% \mathrm{NaCl}$ to a final concentration of $0.1 \mathrm{nmol} / \mathrm{ml}$. Following this step, the stained BES were placed face down on a chambered cover glass filled with $20 \mu l 0.9 \% \mathrm{NaCl}(1 \mu \mathrm{l}$-Slide eight well ibiTreat, ibidi, Munich, Germany) and analyzed using either a $63 \times$ water immersion objective (HCX PL APO/bd. BL, $63.0 \times 1.2 \mathrm{~W}$, Leica) of CLSM (Leica TCS SP2 AOBS, Leica) for mature biofilms (3 days) or using an Axio Observer Z1 (Carl Zeiss Microscopy, Jena, Germany) with a $63 \times$ oil immersion objective (Plan-APOCHROMAT, $63.0 \times$ 1.4 Oil, Carl Zeiss Microscopy) for initial biofilms ( $2 \mathrm{~h}$ ).

For quantification of the viable biofilm after aPDT and in the control groups, the mature biofilm (3 days) was screened at three representative positions. This resulted in a total of 12 biofilm locations per participant in the four BES to be tested. At each of the three biofilm points, upper and lower boundaries were determined to calculate the mean thickness of the biofilm then scanned in the $Z$ direction, resulting in optical sections about $0.5 \mu \mathrm{m}$ thick, which were taken at $2 \mu \mathrm{m}$ intervals throughout the biofilm layers. To reduce the risk of spectral overlap, sequential scanning was used. Each optical section was taken as an image of $1024 \times 1024$ pixels. The zoom factor was set to $1.7 \times$, corresponding to physical dimensions of 140 by $140 \mu \mathrm{m}$ per image. In order to increase the number of results in the quantification of viable initial biofilms $(2 \mathrm{~h})$ after aPDT, five representative locations were screened per BES. Single images were taken which resulted in a total of 30 biofilm locations in the six BES to be tested. In order to reduce stray fluorescence signal arising from out-of-focus light, an Apotome. 2 system (Carl Zeiss Microscopy) was utilized. By this method, the system created three images using different grid positions placed in the beam path and automatically calculated the optical section so that only the focal plane was detected.

\section{Image analysis}

Image analysis of the mature biofilm (3 days) was carried out as described elsewhere [48]. For the evaluation, a maximal projection for each image stack was generated by LSM Image Browser 5 (Zeiss; Oberkochen, Germany) and the covering grades of the scanned biofilm points were quantified. For further biofilm analysis, the red and green image stacks were analyzed using MetaMorph 6.3r7 (Molecular Devices Corporation; CA, USA). The intensity thresholds were set manually and separately for each channel of the image stack to define the total surface populated by viable and nonviable microorganisms. For the analysis of the initial biofilm $(2 \mathrm{~h})$, which consisted of single images per position, the program ImageJ 1.50i (Wayne Rasband, National Institutes of Health; MA, USA) was used to evaluate the number of pixels in the red-green projection. After manually setting the threshold, the number of pixels for live and dead bacteria could be counted and the ratio of viable to nonviable microorganisms was determined. The statistical significance of the resulting covering grades (in \%) of living and dead cells within the biofilm region was investigated.

\section{Statistical analysis}

For descriptive analysis, the mean and standard deviation were computed. To compare subgroups, linear mixed models with random intercepts for each probing and participant as clusters were applied. For correction of the multiple testing problem (adjustment of p-values), Bonferroni test was used. A Friedman test was used to show differences between the groups in cases of strict not normally distributed data. The statistical analysis was done with STATA 14.2.

\section{Results}

APDT in combination with ICG significantly reduces the number of different oral pathogenic microorganisms.

Figure $4 \mathrm{~A}$ and $\mathrm{B}$ show the eradication rates of $S$. mutans and E. corrodens after application of aPDT using ICG in combination with VIS+wIRA, as well as the untreated negative control and positive control with CHX. APDT 
(A)

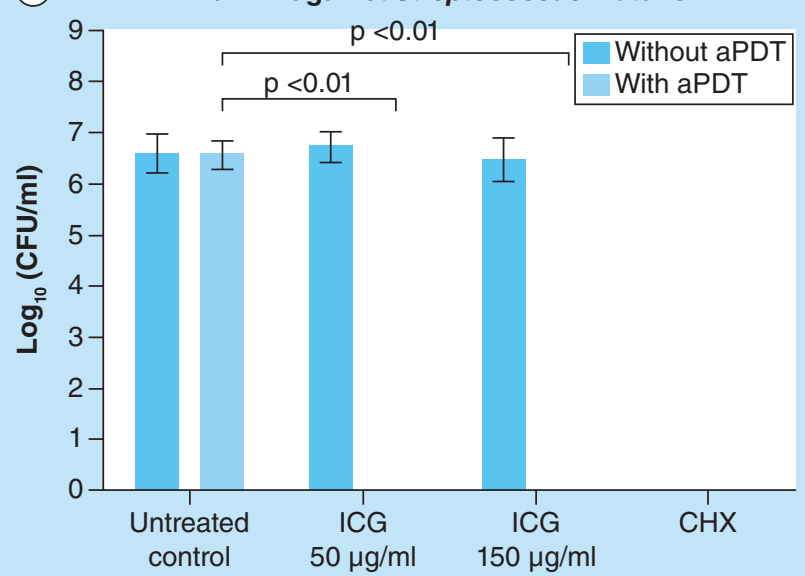

(C)

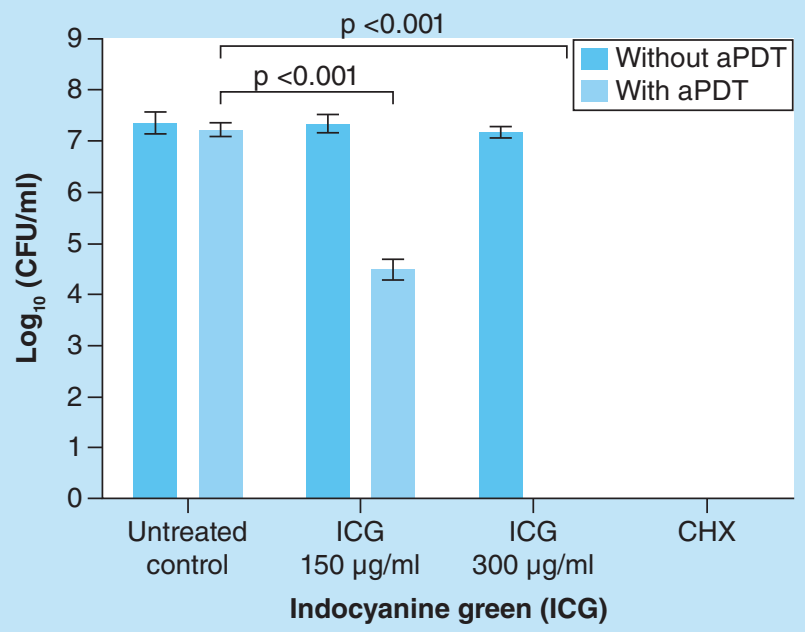

(B)

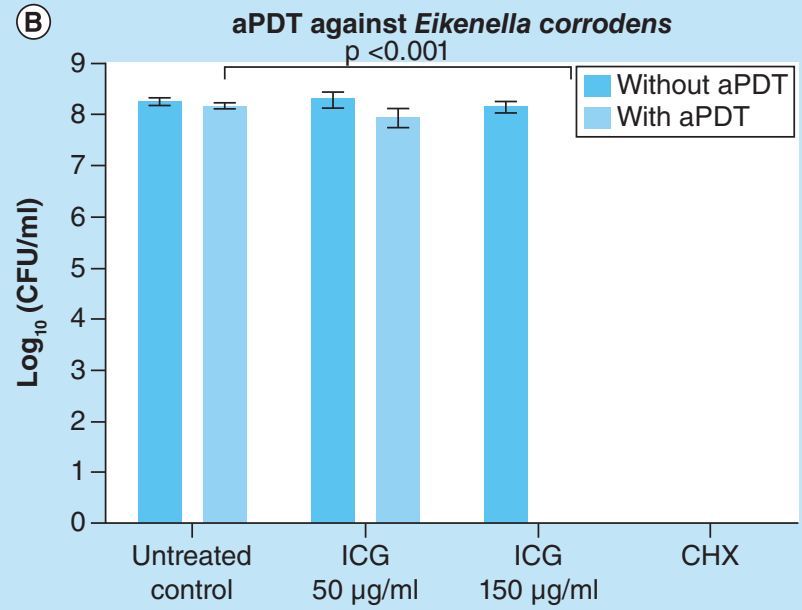

(D)

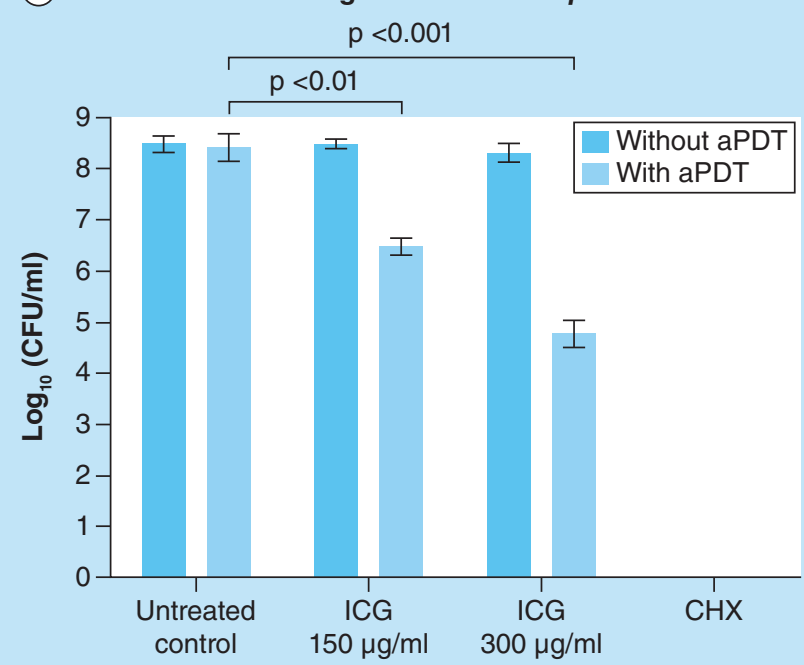

(E) aPDT against Enterococcus faecalis

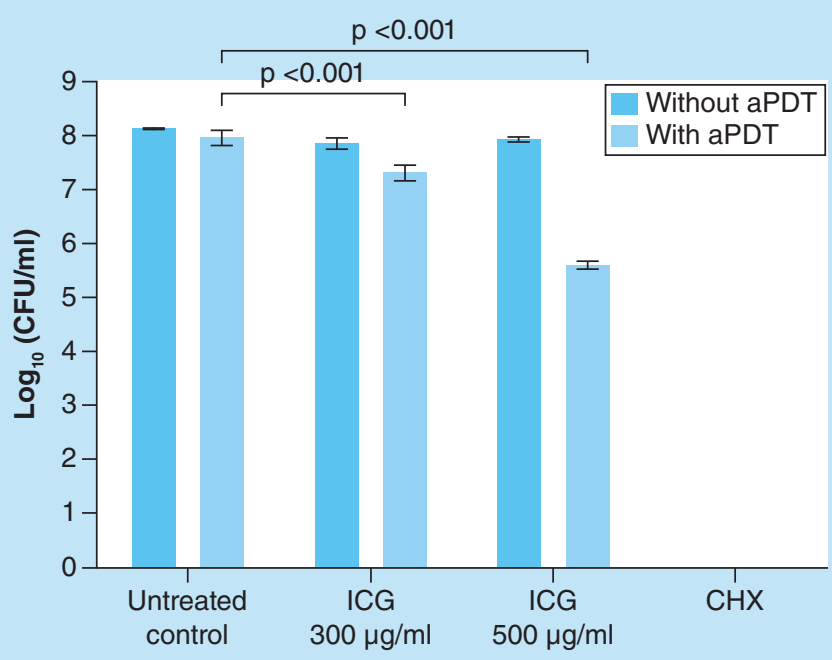

Figure 4. Graphs of the numbers of colony forming units showing photodynamic efficacy against various periodontal pathogens previously grown as overnight cultures in vitro. The concentrations of the used photosensitizer indocyanine green, an untreated negative control and a CHX-treated positive control are shown both with and without the use of aPDT. The CFU are displayed on a $\log _{10}$ scale per milliliter $\left(\log _{10} \mathrm{CFU} / \mathrm{ml}\right)$. All significant $\mathrm{p}$-values are marked on the graphs. aPDT: Antimicrobial photodynamic therapy; CFU: Colony forming unit; CHX: Chlorhexidine; ICG: Indocyanine green. 
showed a significant elimination ( $\mathrm{p}<0.001$ ) of $S$. mutans $\left(4 \log _{10} \mathrm{CFU}\right.$ ), already at a concentration of $50 \mu \mathrm{g} / \mathrm{ml}$ ICG, which corresponds to an eradication rate of $99.99 \%$. In the case of E. corrodens, significant eradication ( $\mathrm{p}=0.002$ ) of $4 \log _{10}$ CFU was achieved only at a concentration of $150 \mu \mathrm{g} / \mathrm{ml}$ ICG compared with the untreated negative control. A high killing effect was also shown for the anaerobic bacteria $F$. nucleatum (Figure 4C) and $V$. parvula (Figure 4D) at an ICG concentration of $150 \mu \mathrm{g} / \mathrm{ml}(\mathrm{p}<0.001, \mathrm{p}=0.002)$. The bacterial count was reduced by a level of $2.7 \log _{10}$ CFU for $F$. nucleatum and $1.9 \log _{10}$ CFU for $V$. parvula, which corresponds to a reduction rate of $\geq 98 \%$. Using higher ICG concentrations of $300 \mu \mathrm{g} / \mathrm{ml}$, a reduction up to $99.99 \%$ for $F$. nucleatum and 99.9\% for $V$. parvula was achieved. In the case of E. faecalis shown in Figure 4E, a smaller, yet significant reduction of $<90 \%$ in the number of CFU at a concentration of $300 \mu \mathrm{g} / \mathrm{ml} \mathrm{ICG}$ was observed $(\mathrm{p}<0.001)$. However, a higher eradication of more than $99 \%\left(2.4 \log _{10} \mathrm{CFU}\right)$ was possible at increased concentrations of $500 \mu \mathrm{g} / \mathrm{ml} \mathrm{ICG}$ $(\mathrm{p}<0.001)$. No cultivable bacteria $\left(0 \log _{10} \mathrm{CFU}\right)$ were detected after treatment with CHX.

\section{ICG with VIS+wIRA significantly reduced the number of planktonic microorganisms within human saliva}

Figure 5A \& B illustrate the rate of elimination of salivary microorganisms after treatment with and without aPDT and in the control groups. Regarding the untreated negative control, the use of VIS+wIRA (6.9-7.0 $\log _{10}$ CFU) on its own has no appreciable effect on the number of salivary bacteria compared with that of the negative control without aPDT (7.0 $\left.\log _{10} \mathrm{CFU}\right)$. Furthermore, the use of $300 \mu \mathrm{g} / \mathrm{ml}$ ICG without aPDT has no major influence on the number of aerobic or anaerobic microorganisms (6.9-7.0 $\left.\log _{10} \mathrm{CFU}\right)$. In contrast, the combination of ICG and VIS+wIRA led to significant eradication $(\mathrm{p}<0.05)$ of up to $3 \log _{10} \mathrm{CFU}$ of aerobic bacteria, as well as to a significant reduction $\left(\mathrm{p}<0.05\right.$ ) of up to $3 \log _{10} \mathrm{CFU}$ of anaerobic microorganisms, signifying a killing rate of 99.9\%. In the positive control using 0.2\% CHX, no bacteria could be detected (0 $\left.\log _{10} \mathrm{CFU}\right)$.

\section{APDT combined with ICG significantly decreased the viable counts of oral microorganisms within initial adhesion \& mature biofilm}

Figure 6A \& B show the eradication of microorganisms from the initial biofilm after $2 \mathrm{~h}$ of formation. The control groups are an untreated negative control with a mean value of about $4.5 \log _{10}$ CFU and a CHX-treated positive control with a mean value of about $0.4 \mathrm{CFU}$ on a $\log _{10}$ scale. Apart from the significant reduction $(\mathrm{p}<0.001)$ by CHX, aPDT in combination with $300 \mu \mathrm{g} / \mathrm{ml} \mathrm{ICG}$ also showed a significant elimination $(\mathrm{p}<0.001)$ of living aerobic $\left(1.1 \log _{10} \mathrm{CFU}\right)$ and anaerobic $\left(0.7 \log _{10} \mathrm{CFU}\right)$ microorganisms. Higher concentrations such as $450 \mu \mathrm{g} / \mathrm{ml}$ ICG with VIS+wIRA led to a complete eradication of the bacteria within the initial biofilm ( $p<0.001)$, so that no microorganisms could be detected $\left(0 \log _{10} \mathrm{CFU}\right)$. Figure $6 \mathrm{C} \& \mathrm{D}$ show that the number of microorganisms in the untreated mature biofilm of aerobic bacteria was $6.9 \log _{10} \mathrm{CFU}$ and the anaerobic bacteria $7.3 \log _{10} \mathrm{CFU}$, respectively. Although CHX was used as a positive control, it shows a reduction to a mean value of $5.4-5.5 \log _{10}$ $\mathrm{CFU}$, corresponding to a significant reduction similar to that seen with the use of aPDT and $300 \mu \mathrm{g} / \mathrm{ml} \mathrm{ICG}$ (5.5-5.9 $\left.\log _{10} \mathrm{CFU}\right)$. A higher elimination of the viable microorganisms to a mean value of $4.4-4.6 \log _{10} \mathrm{CFU}$ was achieved only with the use of aPDT and $450 \mu \mathrm{g} / \mathrm{ml}$, and corresponds to an eradication rate of oral microorganisms more than $99 \%$.

\section{Live/dead assays showed a high bactericidal effect for aPDT in combination with ICG against oral biofilms}

The quantitative results of the surviving microorganisms after application of VIS+wIRA with ICG, as well as for the CHX-treated positive control and the untreated negative control are illustrated in Figure 7 after formation periods of $2 \mathrm{~h}$ and 3 days in boxplots. While $99 \%$ of the bacteria that cover the specimen at the initial adhesion in Figure $7 \mathrm{~A}$ are viable in the untreated control, the statistical analysis revealed a substantial difference $(\mathrm{p}<0.001)$ in the percentage of vital bacteria in biofilms treated with CHX (3\%) or with ICG-mediated aPDT (6\%). The results with mature biofilm depicted in Figure 7B showed similar significant differences $(p<0.001)$ in the amount of vital bacteria remaining in the positive control with CHX (27\%), as well as in the groups treated with aPDT combined with $300 \mu \mathrm{g} / \mathrm{ml}(26 \%)$ or $450 \mu \mathrm{g} / \mathrm{ml}$ (8\%) ICG as compared with the untreated control (82\%). In fact, in the presence of $450 \mu \mathrm{g} / \mathrm{ml}$ ICG, significantly more microorganisms were killed within the biofilm $(\mathrm{p}<0.001)$ compared with lower ICG-concentrations, or compared with the treatment with CHX. The percentages presented above are all median values. Figure 8 shows representative live/dead-CLSM images of aPDT-treated initial biofilm (2 h) using VIS+wIRA and ICG as a photosensitizer. Concerning the untreated control in Figure 8A, isolated dense 
(A) aPDT against aerobic salivary bacteria

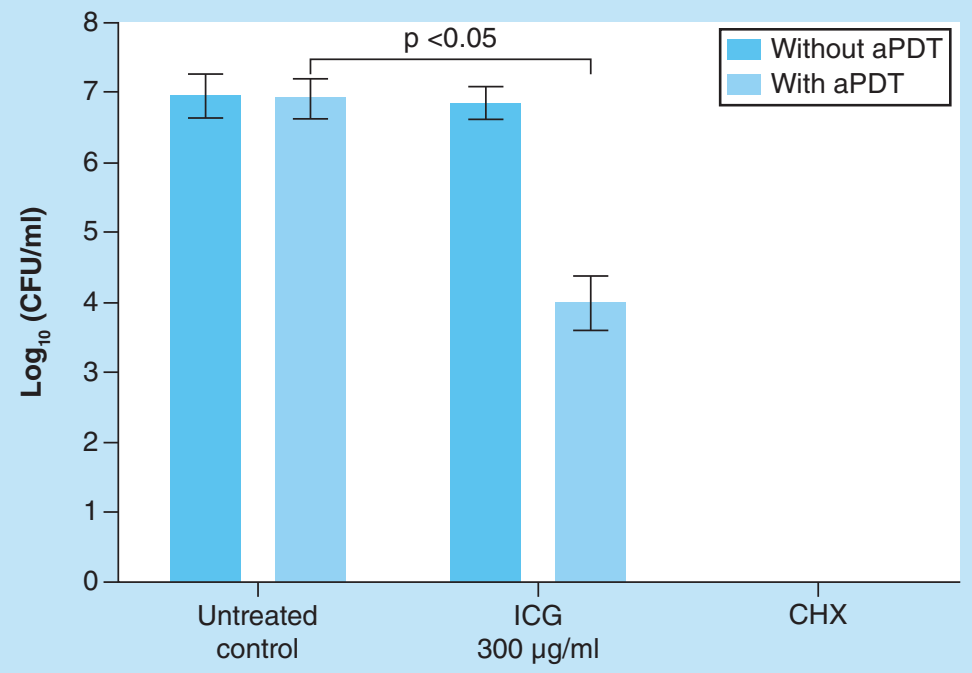

(B)

aPDT against anaerobic salivary bacteria

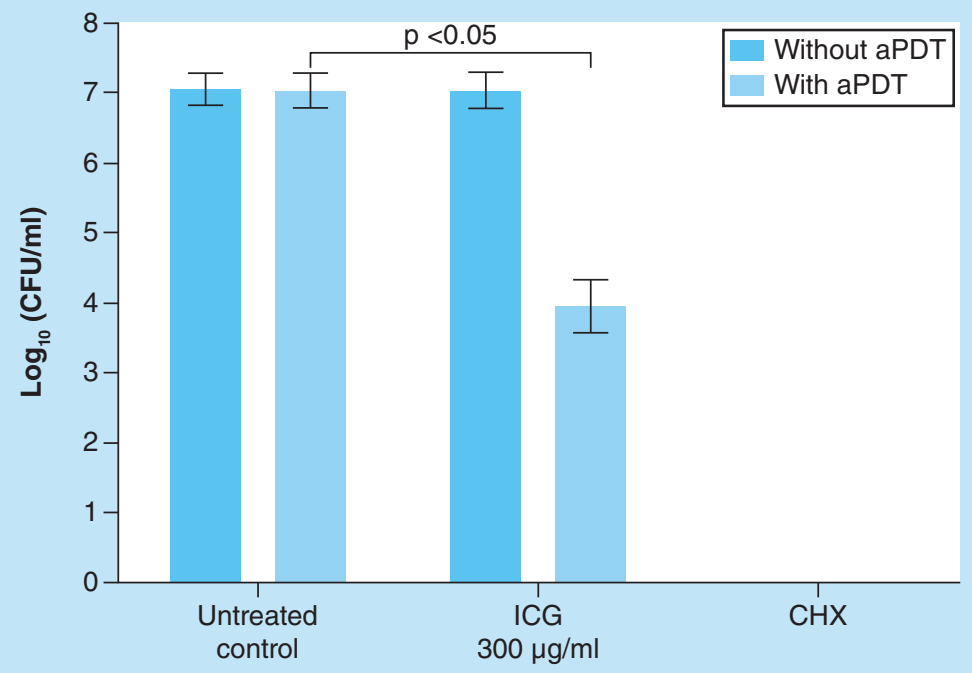

Figure 5. Diagrams of the reduction of planktonic microorganisms in total human saliva after use of indocyanine green in combination with and in the absence of visible light and water-filtered infrared A radiation. In addition to the untreated negative control and the $0.2 \%$ chlorhexidine-treated positive control, the concentration of $300 \mu \mathrm{g} / \mathrm{ml}$ ICG used was determined based on earlier in vitro experiments. The CFUs are presented on a $\log _{10}$ scale per milliliter $\left(\log _{10} \mathrm{CFU} / \mathrm{ml}\right)$.

aPDT: Antimicrobial photodynamic therapy; CFU: Colony forming unit; ICG: Indocyanine green.

accumulations of viable bacteria (green) and very few nonviable cells (red) on the BES were detected. In contrast to the dense spatial structures of initially formed biofilm in the negative controls, the composite of the microorganisms after using VIS+wIRA with ICG (Figure 8B) or treatment with CHX (Figure 8C) appeared resolved. In addition to the rather homogeneous distribution, which is probably due to the detachment of nonviable cells, aPDT as well as $\mathrm{CHX}$ caused cell death of the majority of the attached bacteria.

\section{CLSM images show a high penetration of ICG using aPDT within the mature biofilm}

Figure 9 displays representative cross-sectional live/dead-CLSM images of aPDT-treated mature biofilm (3 days) using VIS+wIRA and ICG as a photosensitizer. Examination of the optical sections of the untreated biofilm (negative control) reveals dense organized structures of viable bacteria (green) in different configurations (Figure 9A). 


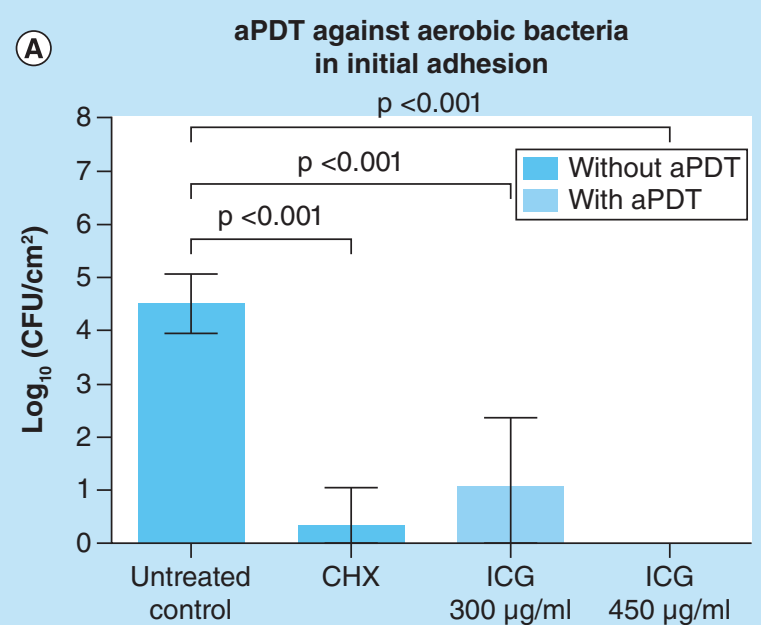

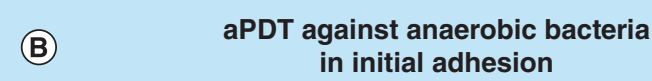

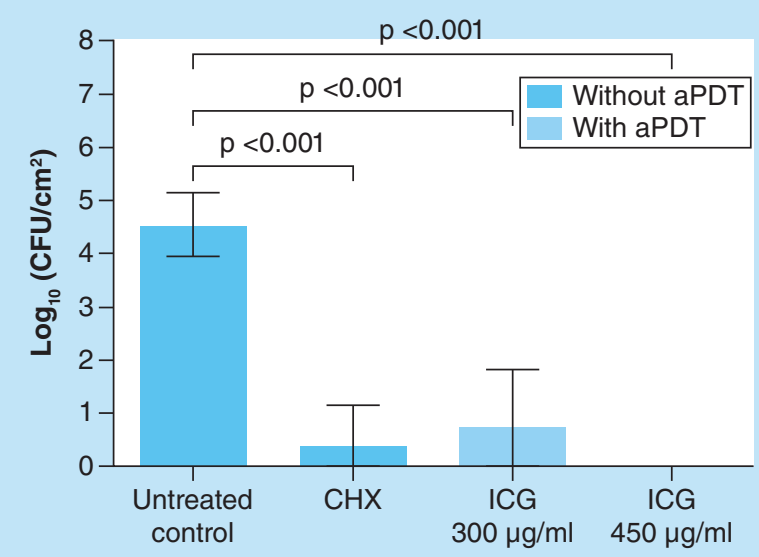

(D)

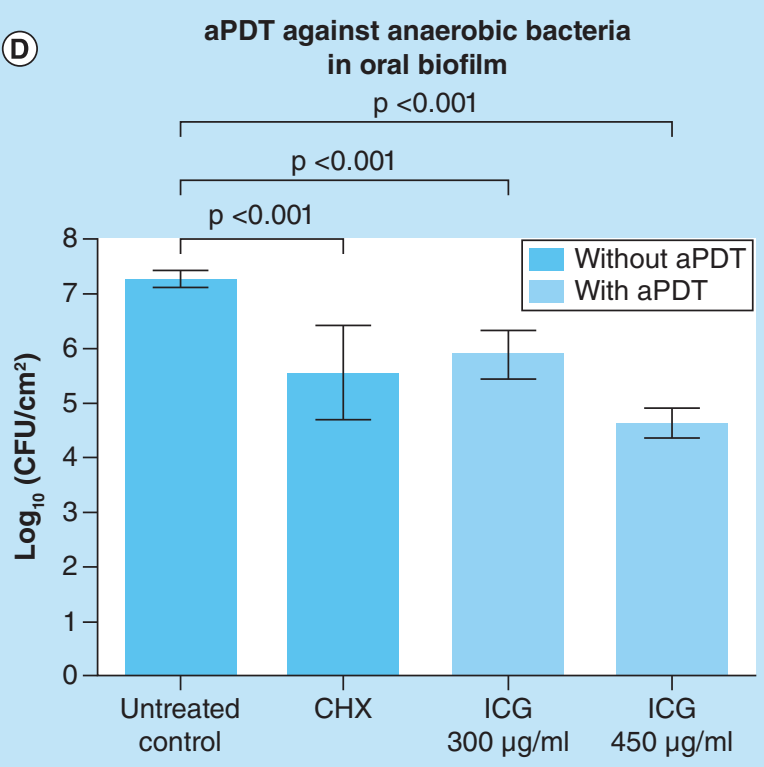

Figure 6. Plots of eradication rates of initially formed biofilms ( $2 \mathrm{~h}$ ) and mature biofilms ( 3 days) after use of Antimicrobial photodynamic therapy in combination with indocyanine green. The control groups are an untreated negative control and a $0.2 \%$ chlorhexidine-treated positive control. The number of CFUs is presented on a $\log _{10}$ scale per square centimeter $\left(\log _{10} \mathrm{CFU} / \mathrm{cm}^{2}\right)$. The significant $p$-values are marked in the diagrams.

aPDT: Antimicrobial photodynamic therapy; CFU: Colony forming unit; CHX: Chlorhexidine; ICG: Indocyanine green.

The mature biofilm shown in Figure 9B appears after treatment with CHX (positive control) differently. Noticeable is a massive loss of cell viability, as depicted by numerous red-stained bacteria. However, many vital microorganisms remain within deeper layers of the biofilm, suggesting a limited ability of chlorhexidine to penetrate it. The biofilms treated with aPDT and either $300 \mu \mathrm{g} / \mathrm{ml}$ ICG (Figure 9C) or $450 \mu \mathrm{g} / \mathrm{ml} \mathrm{ICG} \mathrm{(Figure} \mathrm{9D)} \mathrm{showed} \mathrm{a} \mathrm{great}$ amount of dead bacterial cells but without any differences regarding biofilm thickness. After visual observation of the CLSM Z-section galleries, the presence of a varied biofilm permeability dependent on the concentration of the photosensitizer was confirmed (Figure 9C \& D). More specifically, the oral biofilm appeared more effectively penetrated at a concentration of $450 \mu \mathrm{g} / \mathrm{ml}$ ICG than at $300 \mu \mathrm{g} / \mathrm{ml} \mathrm{ICG}$, as seen from the decreasing number of viable microorganisms in the cross-sectional images after exposure to VIS+wIRA. 

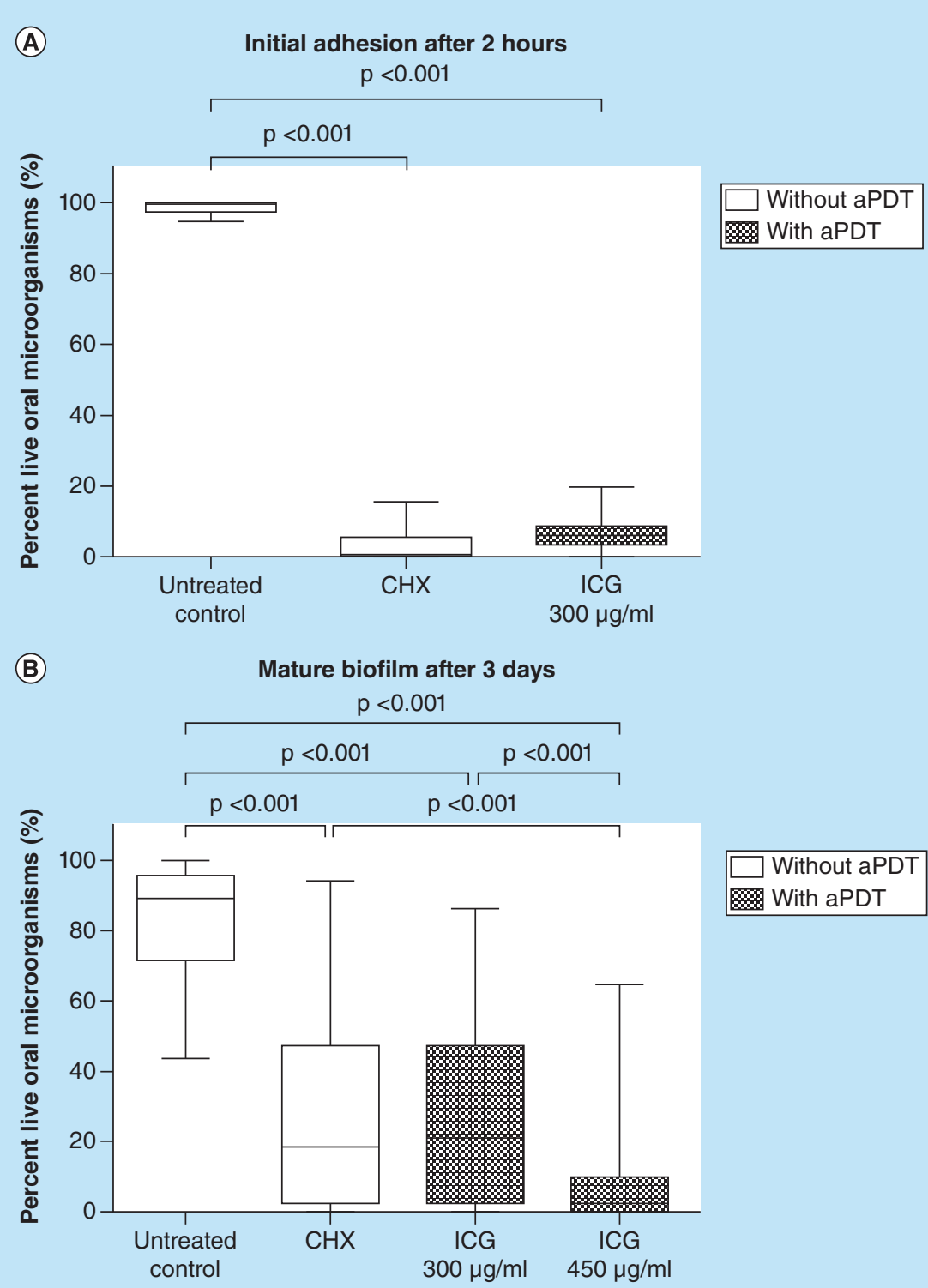

Figure 7. Boxplots depicting percentages of the live bacterial cells following live/dead staining after $2 \mathrm{~h}$ (initial adhesion) and 3 days (mature biofilm), and Antimicrobial photodynamic therapy with indocyanine green as a photosensitizer. The untreated negative control and $0.2 \% \mathrm{CHX}$-treated positive control were also tested. The whiskers indicate minimum and maximum, while the median is represented by the internal line in each box. The significant $p$-values are provided.

aPDT: Antimicrobial photodynamic therapy; CHX: Chlorhexidine; ICG: Indocyanine green.

\section{Discussion}

The present report underlines the effectiveness of an innovative antimicrobial photodynamic approach using aPDT with VIS+wIRA in combination with ICG to treat oral pathogenic bacteria, as well as in situ-formed initial and mature oral biofilms. ICG was originally used in the medical field as a diagnostic tool for the study of liver function, ophthalmology and dermatology [49]. Following application to the tissue, the dye is almost completely bound to globulins $(80 \%)$ and albumin $(20 \%)$, thereby remaining predominantly intravascular and evenly distributed throughout the circulating blood [50]. Its exclusive elimination via the liver prevents accumulation in the body, making ICG nontoxic and well tolerated [51]. Side effects are rare and those that appear are possibly due to the 5\% sodium iodide contained in the preparation to improve the lessening [11]. Severe side effects have only been described in isolated instances. These include anaphylactic shock, hypotension, tachycardia, dyspnea and urticaria [52]. Due to 

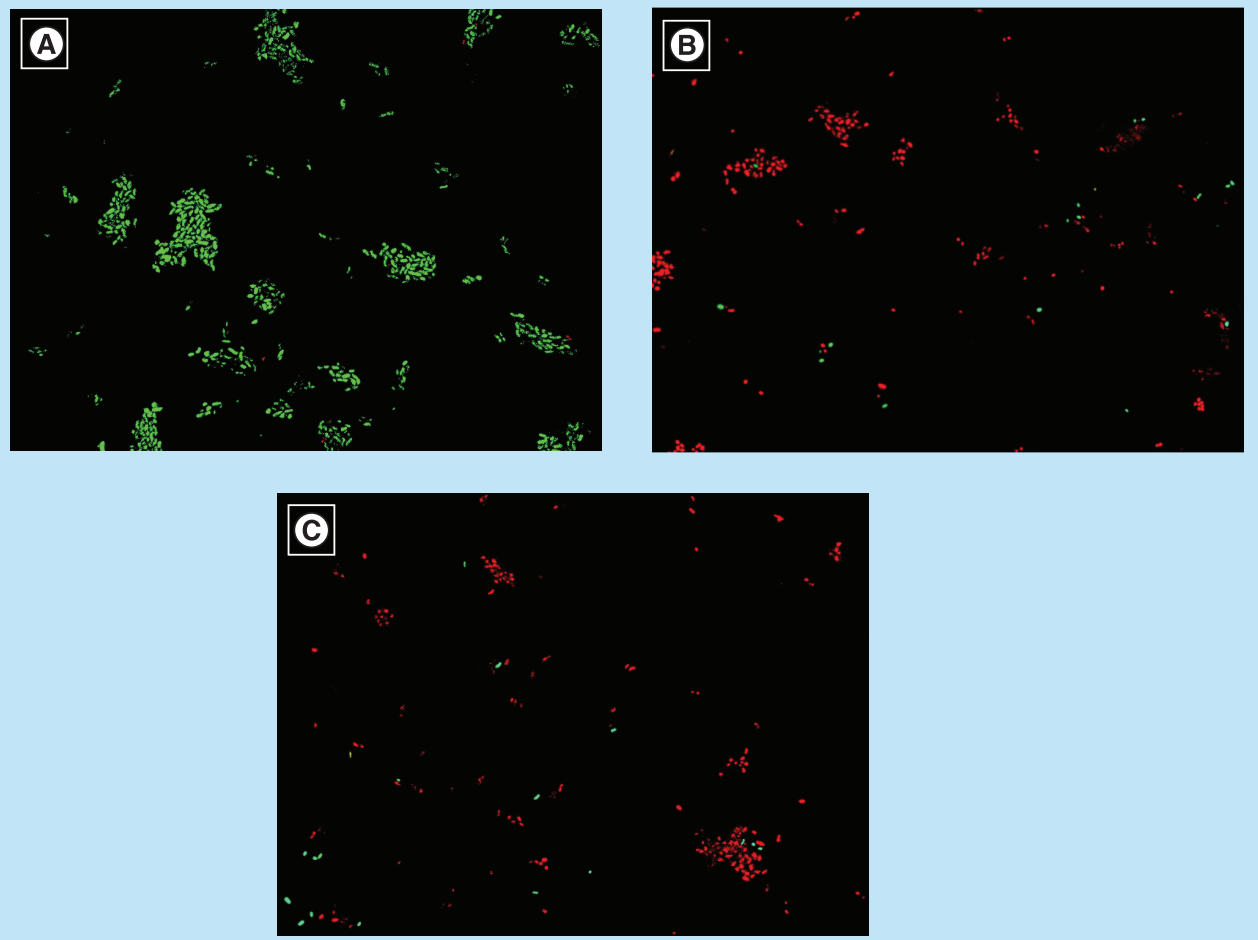

Figure 8. Widefield live/dead images demonstrating the effect of antimicrobial photodynamic therapy on initially formed biofilm $2 \mathrm{~h}$. Illustrated are live (green) and dead (red) bacterial cells within the untreated negative control (A), chlorhexidine-treated positive control (B), and Antimicrobial photodynamic therapy-treated biofilms after using indocyanine green (C) in the presence of visible light and water-filtered infrared A radiation. Each image displays maximum projections of the examined surface area.

fluorescent properties in the near infrared range, this provides new possibilities, especially in the field of oncology, to detect tumors for example, or to eliminate malignant tissue under irradiation due to the formation of ROS and the hyperthermia effect, respectively [53].

ICG has been recently added, especially for prophylactic use in the field of dentistry, to dyes such as MB and $\mathrm{TB}$, which have successfully been used in the application of aPDT [2,54]. In addition to prevention, photodynamic disinfection in the field of oral surgery and implantology for the sterilization of bone cavities is also possible [14]. This noninvasive form of therapy with photosensitizers like MB and TB involves light-induced athermal inactivation of microorganisms without destruction of the surrounding tissue on the basis of light-absorbing dyes, which via release of an oxygen radical, either singlet or triplet oxygen, leads to an oxidizing effect on the bacterial membrane and thus its irreversible damage [28]. In case of ICG, most of the absorbed light is released in the form of heat so that a predominantly photothermal effect in combination with a photodynamic effect is described [55,56]. In this context, tissue damage by heat is possible, so the laser energy and treatment time must be adjusted. In contrast to other photosensitizers, the reaction with ICG is more specific and safer. The combination of PDT (photodynamic)/PTT (photothermic) by using ICG applications enables saving tissue, as well as sterilization and improved healing [28]. There is still a controversial debate in the case of ICG as to whether the photo-oxidative effect contributes directly to the therapy or just to the photothermal effect [28]. Whether and how important the influence of the photo-oxidative effect actually still needs to be further investigated. However, thermal effects, such as overheating and unspecific reactions generated by the light source itself (e.g., by diode laser), can be eliminated by using VIS+wIRA [57].

The innovation of this study is the application of different concentrations of ICG to a broad spectrum of bacteria using VIS+wIRA as a light source. Technically, a halogen lamp can generate VIS+wIRA, a broad-band heat radiation with unpolarized light emission ranging between 570 and $1400 \mathrm{~nm}$ [58]. After radiation enters the water filter, harmful infrared $\mathrm{B}$ and $\mathrm{C}$ radiation is absorbed, and the remaining infrared A radiation can pass through deeper tissues at low thermal stress [59]. For a long time, the use of VIS+wIRA was limited primarily to the field of 

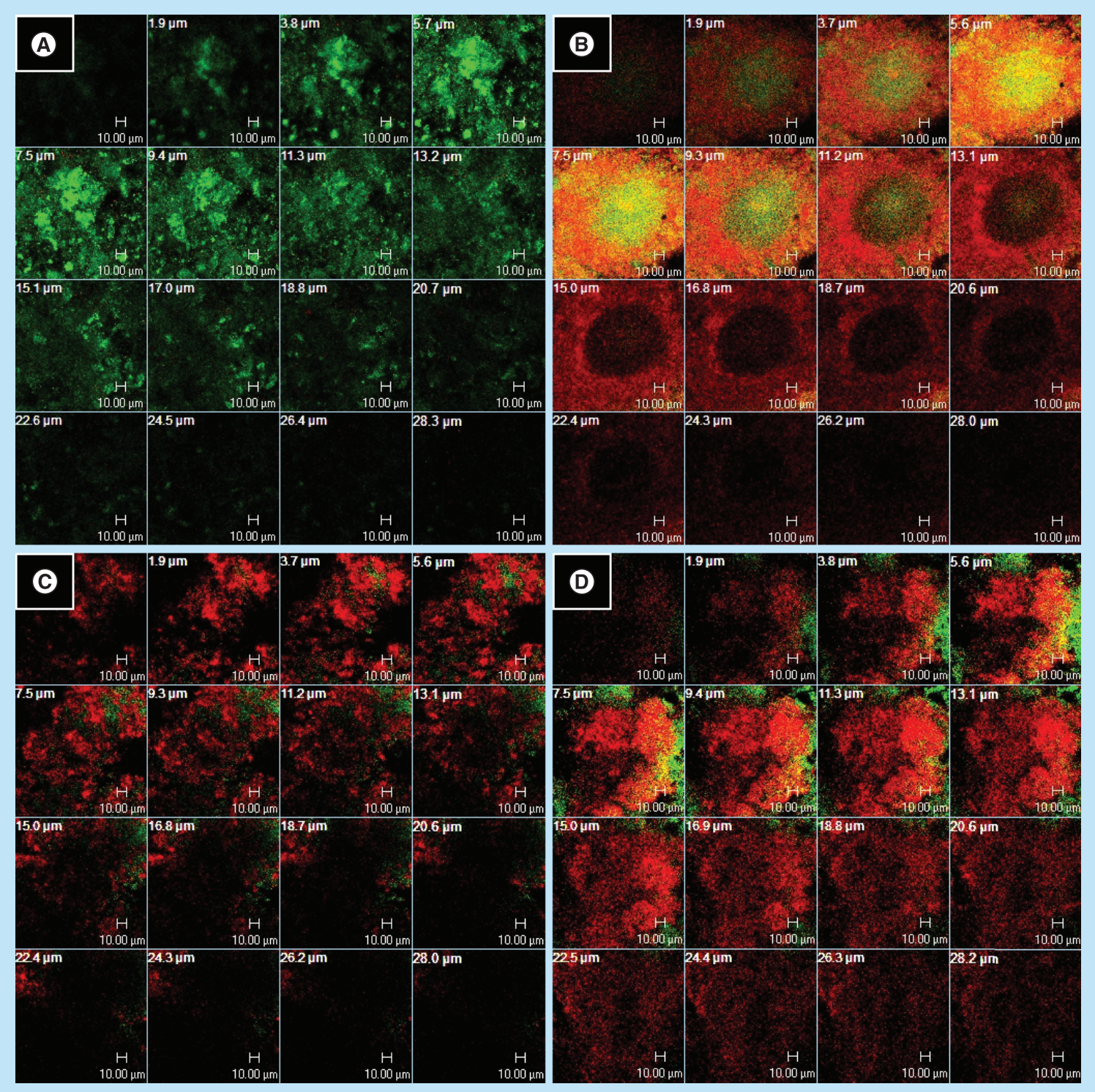

Figure 9. Z-section galleries of representative live/dead-and confocal laser scanning microscopy images of

Antimicrobial photodynamic therapy-treated mature biofilms (3 days). The panels illustrate the live (green) and dead (red) bacterial cells of the untreated negative control (A), chlorhexidine-treated positive control (B), and

Antimicrobial photodynamic therapy-treated biofilms in the presence of either $300 \mu \mathrm{g} / \mathrm{ml}$ indocyanine green (C) or $450 \mu \mathrm{g} / \mathrm{ml}$ indocyanine green (D). Vertical sectioning was used to generate multiple Z-sections at $2 \mu \mathrm{m}$ intervals through the sample above the surface, respectively. Scale bars represent a length of $10 \mu \mathrm{m}$.

dermatology where it has been used against skin tumors, wounds and pain [60,61]. The further introduction into the microbiology for the photoinactivation of diverse pathogens can be related to the high antimicrobial effectiveness of VIS+wIRA [24]. In order to focus on the proportion of emitted radiation which is infrared A (wIRA; in the range of 780-1400 nm), an accessory orange filter (within the range of $570-780 \mathrm{~nm}$ ) can be added to the visible light source [62]. The high energy of the radiation leads to an increase in the metabolic rate. This in turn produces a greater amount of oxygen transferred to deeper tissue layers, while at the same time avoiding thermal stress on the tissue surface [63]. Consistent with our findings from in vitro experiments, another study has found that the possible slight increase in temperature due to VIS+wIRA in the absence of a photosensitizer does not seem to cause any appreciable cell destruction [63]. Although comparable LED devices are low in cost, their emission wavelength spectrum is often quite limited and their use as a light source can lead to tissue overheating [63]. Furthermore, 
radiators emitting VIS+wIRA are less painful than LED devices and safe when applied at different treatment doses up to $30 \mathrm{~min}[40,64,65]$. However, in the present study, the treatment duration of 5 min proved effective, which also seems realistic for its application in the dental practice.

Significant reduction of selected bacteria that are commonly found in the oral cavity can only be accomplished when aPDT is combined with bacterial-specific concentrations of ICG. In these cases, eradication rates of up to 99.99\% can be reached as shown by the present results (Figure 4). The complete elimination of some bacteria associated with periodontitis, such as F. nucleatum, using aPDT with ICG could be demonstrated in the present study at ICG-concentrations of $300 \mu \mathrm{g} / \mathrm{ml}$ and showed results similar to those in a study by Kranz et al [66]. The authors examined the influence of Trolox ${ }^{\top \mathrm{M}}$, a Vitamin $\mathrm{E}$ analog, during aPDT with ICG and Near-IR-laser $(810 \mathrm{~nm}$, NIR) on periodontal pathogens. High concentrations of ICG $(500 \mu \mathrm{g} / \mathrm{ml})$ without Trolox eliminated $F$. nucleatum and Porphyromonas gingivalis completely while temperatures of over $59^{\circ} \mathrm{C}$ were measured, whereas the addition of $2 \mathrm{mM}$ vitamin $\mathrm{E}$ analog eliminated these germs completely already with lower ICG-concentrations $(250 \mu \mathrm{g} / \mathrm{ml})$ and temperatures of about $50^{\circ} \mathrm{C}$. The authors concluded that the combination of ICG and a vitamin $\mathrm{E}$ analog in aPDT reduces the damaging photothermal impact and favors the photo-oxidative effect [37]. Considering that the NIR light source used by Kranz et al. [66] also led to an additional thermal effect, the results with ICG/Trolox are comparable with our results using VIS+wIRA. Furthermore, with the use of ICG we were also able to detect complete elimination of $S$. mutans, one microorganism associated with caries development as confirmed in another in vitro study [67]. Azizi et al. [67] examined MB (2\%) with ICG $(0.2 \%=200 \mu \mathrm{g} / \mathrm{ml})$ as a photosensitizer in aPDT against $S$. mutans contaminated molars. A diode laser $(660$ and $810 \mathrm{~nm}$, respectively) was used as the light source. The authors showed that after irradiating for $60 \mathrm{sec}$ and then incubating for $24 \mathrm{~h}$ a complete elimination of bacteria could be detected as determined by CFU. In this study, we used different concentrations of ICG compared with those used by Azizi et al. [67]. At ICG-concentrations of $50 \mu \mathrm{g} / \mathrm{ml}$, a total elimination of $S$. mutans was measured. In an in vitro study, Beltes et al. [31] examined how the growth of a planktonic $E$. faecalis strain was inhibited by NIR irradiation in combination with ICG, with regard to endodontic infections. The ICG-concentration used was $100 \mu \mathrm{g} / \mathrm{ml}$. The evaluation showed that all approaches to irradiation (different fluence rates and energy doses) and ICG showed significant reduction in bacteria of between approximately $5.1-5.3 \log _{10}$ in viable counts whereas when the treatment was with laser or photosensitizer alone, there was no reduction of $E$. faecalis. In the present study, the growth of $E$. faecalis was significantly reduced $\left(2.3 \log _{10}\right)$ with VIS+wIRA when combined with ICG at concentrations of $500 \mu \mathrm{g} / \mathrm{ml}$, with a killing effect of more than $99.9 \%$. Furthermore, aPDT with ICG at a concentration of $150 \mu \mathrm{g} / \mathrm{ml}$ also significantly eliminated E. corrodens $(99.99 \%)$ and significantly reduced V.parvula (>99.9\%). This could be caused by the Gram-negative cell wall of $V$. parvula, which may lead to low permeability of ICG. Our results obtained with VIS+wIRA on planktonic bacteria showed the antimicrobial effect was dependent on the ICG concentration used. Topaloglu et al. [68,69] reported on the risk that lower ICG concentrations used during aPDT cannot only eliminate bacteria but actually increase the proliferation rate of bacteria, as demonstrated in in vitro experiments with P. aeruginosa [29]. This was explained by the amount of ROS, which was generated and determined the actual level of bactericidal effect or proliferation.

In addition to the positive properties of aPDT when combined with ICG already mentioned, there are further advantages in the dental field as described by Meisel and Kocher [70]. These include a possible eradication of bacteria in hard-to-reach niches such as tooth pockets in the case of periodontitis [71] or the surfaces of implants [72]. Mechanical treatments for biofilm removal lead to increased dentin sensitivity and could then be omitted. Furthermore, the risk of bacteremia and periodontal systemic diseases such as heart disease and diabetes could be reduced.

Naturally occurring biofilms are usually made up of a network of strains from a broad spectrum of bacteria rather than a single strain. To more closely approach this condition, saliva was obtained from healthy study participants and also applied with VIS+wIRA in combination with ICG. These experiments also showed a significant reduction in bacteria, roughly correlating with an eradication rate of $99.99 \%$. In contrast, the use of either VIS+wIRA or ICG on their own showed no bacterial reduction. However, one must consider that microorganisms living in biofilms are up to 1000-times more resistant to antimicrobials than their planktonic counterparts [73]. For this reason, our present investigation into the effect of aPDT in combination with ICG on in situ formed biofilms seemed reasonable.

To the best of our knowledge, this is the first time that aPDT with VIS+wIRA in combination with the photosensitizer ICG have been used to treat in situ oral biofilms. Most publications dealing with the antimicrobial effects of aPDT using ICG are conducting their studies on planktonic cultures, with only a few investigating its use on bacterial biofilms. However, it must be taken into account that until now, the results regarding aPDT in 
combination with ICG were obtained using a diode laser as a light source and that possible tissue damage due to the thermal effect cannot be excluded. Since the killing effect of microorganisms within the mature oral biofilm was limited to $3 \log$, repeated treatments are recommended to overcome the doubling time of bacteria which could be less than $1 \mathrm{~h}$. Nevertheless, such killing rates would have destroyed the balance of the mature oral biofilm, as it has been shown in detail in our earlier study [39].

The use of bovine enamel as performed in the present study simulates a bacterial attachment to human enamel as it has common physicochemical features with human tooth surfaces. The use of artificial tooth substrata was avoided due to the altered biofilm composition compared with that on natural tooth surfaces [74]. Quantification of CFU after irradiation of the oral biofilm showed a significant reduction at the concentrations of ICG tested, with a correlation between the amount of photosensitizer and the rate of eradication. Furthermore, it was demonstrated that an ICG-based aPDT had an erosive effect on the carious hard tissue, depending on laser irradiation and the concentration of the dye [75,76]. Beltes et al. [31] examined the effect of ICG under NIR irradiation to $E$. faecalis in infected root canals ex vivo. The authors found that aPDT using NIR in combination with $100 \mu \mathrm{g} / \mathrm{ml}$ ICG reduced the $E$. faecalis viable count by a level of $99.99 \%\left(4 \log _{10} \mathrm{CFU}\right)$. However, the bacterial culture in the infected root canals was $72 \mathrm{~h}$ old compared with the E. faecalis culture treated overnight in the present study.

Beytollahi et al. [33] compared the effects of ICG versus TB combined with a diode laser on the formation of biofilm in $S$. mutans. The authors found that increasing photosensitizer concentrations resulted in a reduction in biofilm formation. The maximum level of reduction was at $1 \mathrm{mg} / \mathrm{ml} \mathrm{ICG}$ and $0.1 \mathrm{mg} / \mathrm{ml} \mathrm{TB}$. At the same time, a change in cell morphology was observed in the aPDT-treated cells compared with the untreated cells, along with the formation of an irregular-looking biofilm and a loss of cell interaction, which was also confirmed by our live/dead staining results. A different approach was presented by a study investigating the influence of sublethal doses of various photosensitizers and diode laser irradiation on biofilm formation of the endodontic bacterium $E$. faecalis [28]. It was shown that ICG-concentrations of $31.2 \mu \mathrm{g} / \mathrm{ml}$ up to $1000 \mu \mathrm{g} / \mathrm{ml}$ without irradiation were able to significantly, although not completely, inhibit bacterial growth. With irradiation, the survival rate was dependent on the light dose. The authors revealed that sublethal doses have an inhibitory effect on bacterial physiology, and that the low dose of ICG tested reduced the bacterial biofilm by $42.8 \%$, more than MB and TB, which each showed a reduction less than $20 \%$. Because a further decrease in the sublethal concentration can actually improve biofilm formation [77], the optimal dose must be determined before application. In the present study, the live/dead staining images illustrate, in addition to majority of the microorganisms dying, there was a change of the dense biofilm upon treatment with VIS+wIRA and ICG compared with the untreated control, indicating an aPDT-induced alteration in biofilm architecture. Chiniforush et al. [78] already mentioned the possible influence on bacterial behavior through the alteration of virulence factors when aPDT is used in combination with ICG, which could in turn also influence biofilm topography. Interestingly, the CLSM images presented in this study visualized viable and nonviable organisms and showed a limited depth of penetration for CHX. These studies also showed that bacteria in deeper layers of the mature biofilm were killed when irradiation was combined with ICG, emphasizing its high permeability within the oral biofilm in this instance. An investigation of Bashkatov et al. [79] has shown that near-infrared light, as used in the aPDT with ICG $(810 \mathrm{~nm})$, penetrates up to $6 \mathrm{~mm}$ into the tissue while wavelengths in the range of $650 \mathrm{~nm}$, used with other photosensitizers, only penetrate to a depth of 3-3.5 mm. Therefore, the depth effect of VIS+wIRA with ICG is extended compared with other established photosensitizers because microorganisms in the adjacent area are also reached.

\section{Conclusion \& future perspective}

In conclusion, due to the recent increase in antibiotic resistance alternative therapies such as aPDT, with its benefits that already resistant bacteria can be eliminated while no resistance to the treatment can be developed, are now a focus of research. The results of the present study with aPDT in combination with ICG and using VIS+wIRA as a light source demonstrated that not only planktonic bacteria or bacteria in saliva but also initial and mature biofilm can be effectively eliminated. These findings indicate that this method could be established as an alternative to chemical and antibiotic treatments, especially in the field of dentistry. Compared with other light sources VIS+wIRA is less painful, thermal stress is reduced and tissue damage is avoided. Further in situ investigations should be carried out to assess optimal ICG concentrations for a wide spectrum of oral pathogens, as well as to clarify if the effect of ICG is more photothermal or photooxidative and to examine these effects on the tissue. Taking the healing effects of wIRA on human tissue into consideration, this technique could prove to be helpful in the treatment of oral diseases such as peri-implantitis and periodontitis, though its use in dentistry should be 
evaluated in future clinical trials. An irradiation setup should be developed for clinical use, particularly within the oral cavity. This type of application should be examined in future clinical studies in vivo.

\section{Summary points}

- Due to the increase of antibiotic resistance, alternative antimicrobial treatments such as antimicrobial photodynamic therapy (aPDT) are required.

- The aPDT using visible light and water-filtered infrared A radiation (VIS+wIRA) in combination with indocyanine green (ICG) was tested against oral pathogenic bacteria, total human salivary bacteria and the in situ initial and mature oral biofilm.

- This novel aPDT strongly reduced the number of different oral pathogenic microorganisms (killing rate $\geq 99.9 \%$ ).

- The number of planktonic microorganisms within human saliva was significantly reduced by ICG and VIS+WIRA.

- The aPDT combined with ICG significantly decreased the viable counts of oral microorganisms within initial adhesion and mature biofilm.

- The aPDT using VIS+WIRA and ICG has the potential to treat periodontitis and peri-implantitis as an adjunct therapy.

\section{Financial \& competing interests disclosure}

This study was supported by the Swiss Dr. Braun Science Foundation and in part by the German Research Foundation (DFG, AL 1179/2-1). The authors have no other relevant affiliations or financial involvement with any organization or entity with a financial interest in or financial conflict with the subject matter or materials discussed in the manuscript apart from those disclosed.

No writing assistance was utilized in the production of this manuscript.

\section{Ethical conduct of research}

The study protocol was reviewed and approved by the local ethics committee (no. 502/13). An explanation and declaration of consent were signed by all participants in advance and are available in writing.

\section{Open access}

This work is licensed under the Attribution-NonCommercial-NoDerivatives 4.0 Unported License. To view a copy of this license, visit http://creativecommons.org/licenses/by-nc-nd/4.0/

\section{References}

Papers of special note have been highlighted as: $\bullet$ of interest; $\bullet \bullet$ of considerable interest

1. Nagata JY, Hioka N, Kimura E et al. Antibacterial photodynamic therapy for dental caries: evaluation of the photosensitizers used and light source properties. Photodiagnosis Photodyn. Ther. 9(2), 122-131 (2012).

2. Sarosi C, Moldovan M, Badea ME. A study on revealing agents in the context of photodynamic therapy in dental medicine - a literature review. Defect Diffus. Forum 376, 54-65 (2017).

3. Pourhajibagher M, Bahador A. An in vivo evaluation of microbial diversity before and after the photo-activated disinfection in primary endodontic infections: traditional phenotypic and molecular approaches. Photodiagnosis Photodyn. Ther. 22, 19-25 (2018).

4. Dobson J, Wilson M. Sensitization of oral bacteria in biofilms to killing by light from a low-power laser. Arch. Oral Biol. 37(11), 883-887 (1992).

5. Garcez AS, Hamblin MR. Methylene blue and hydrogen peroxide for photodynamic inactivation in root canal - a new protocol for use in endodontics. Eur. Endod. J. 2(1), 29-29 (2017).

6. Narayanan LL, Vaishnavi C. Endodontic microbiology. J. Conserv. Dent. JCD 13(4), 233-239 (2010).

7. Fontana C, Abernethy A, Som S et al. The antibacterial effect of photodynamic therapy in dental plaque-derived biofilms. J. Periodontal Res. 44(6), 751-759 (2009).

8. Wood S, Nattress B, Kirkham J et al. An in vitro study of the use of photodynamic therapy for the treatment of natural oral plaque biofilms formed in vivo. J. Photochem. Photobiol. B. 50(1), 1-7 (1999).

9. Tavares LJ, Pavarina AC, Vergani CE, de Avila ED. The impact of antimicrobial photodynamic therapy on peri-implant disease: what mechanisms are involved in this novel treatment? Photodiagnosis Photodyn. Ther. 17, 236-244 (2017).

10. Jurič IB, Plečko V, Pandurić DG, Anić I. The antimicrobial effectiveness of photodynamic therapy used as an addition to the conventional endodontic re-treatment: a clinical study. Photodiagnosis Photodyn. Ther. 11(4), 549-555 (2014). 
11. Chiniforush N, Pourhajibagher M, Shahabi S, Bahador A. Clinical approach of high technology techniques for control and elimination of endodontic microbiota. J. Lasers Med. Sci. 6(4), 139-150 (2015).

12. Diogo P, Fernandes C, Caramelo F et al. Antimicrobial photodynamic therapy against endodontic Enterococcus faecalis and Candida albicans mono and mixed biofilms in the presence of photosensitizers: a comparative study with classical endodontic irrigants. Front. Microbiol. 8, 498 (2017).

13. Meimandi M, Ardakani MRT, Nejad AE, Yousefnejad P, Saebi K, Tayeed MH. The effect of photodynamic therapy in the treatment of chronic periodontitis: a review of literature. J. Lasers Med. Sci. 8(Suppl. 1), S7-S11 ( 2017).

14. Nagayoshi M, Nishihara T, Nakashima K et al. Bactericidal effects of diode laser irradiation on Enterococcus faecalis using periapical lesion defect model. ISRN Dent. 2011, 870364 (2011).

15. Faria PEP, Felipucci DNB, Simioni AR, Primo FL, Tedesco AC, Salata LA. Effects of photodynamic process (PDP) in implant osseointegration: a histologic and histometric study in dogs. Clin. Implant Dent. Relat. Res. 17(5), 879-890 (2015).

16. Cieplik F, Tabenski L, Buchalla W, Maisch T. Antimicrobial photodynamic therapy for inactivation of biofilms formed by oral key pathogens. Front. Microbiol. 5, 405 (2014).

-• Review depicting the use of different photosensitizers and light sources for the antimicrobial photodynamic inactivation of oral pathogens.

17. Araújo TSD, Rodrigues PLF, Santos MS et al. Reduced methicillin-resistant Staphylococcus aureus biofilm formation in bone cavities by photodynamic therapy. Photodiagnosis Photodyn. Ther. 21, 219-223 (2018).

18. Azizi B, Budimir A, Bago I et al. Antimicrobial efficacy of photodynamic therapy and light-activated disinfection on contaminated zirconia implants: an in vitro study. Photodiagnosis Photodyn. Ther. 21, 328-333 (2018).

19. Decker EM, Bartha V, von Ohle C. Improvement of antibacterial efficacy through synergistic effect in photodynamic therapy based on thiazinium chromophores against planktonic and biofilm-associated periodontopathogens. Photomed. Laser Surg. 35(4), 195-205 (2017).

20. Karygianni L, Ruf S, Follo M et al. Novel broad-spectrum antimicrobial photoinactivation of in situ oral biofilms by visible light plus water-filtered infrared A. Appl. Environ. Microbiol. 80(23), 7324-7336 (2014).

- One of the first articles introducing the Antimicrobial photodynamic therapy using visible light and water-filtered infrared A radiation in combination with other photosensitizers.

21. Hoffmann G, Hartel M, Mercer JB. Heat for wounds - water-filtered infrared-A (wIRA) for wound healing - a review. Ger. Med. Sci. 14, Doc08 (2016).

-• Review depicting the different healing effects of water-filtered infrared A radiation.

22. Künzli BM, Liebl F, Nuhn P, Schuster T, Friess H, Hartel M. Impact of preoperative local water-filtered infrared a irradiation on postoperative wound healing: a randomized patient - and observer-blinded controlled clinical trial. Ann. Surg. 258(6), 887-894 (2013).

23. Hoffmann G. Water-filtered infrared-A (wIRA) in acute and chronic wounds. GMS Krankenhaushygiene Interdiszip 4(2), Doc12 (2009).

24. Al-Ahmad A, Tennert C, Karygianni L, Wrbas KT, Hellwig E, Altenburger MJ. Antimicrobial photodynamic therapy using visible light plus water-filtered infrared-A (wIRA). J. Med. Microbiol. 62(3), 467-473 (2013).

25. US FDA. Approval 'IC-Green' (1959). www.accessdata.fda.gov/scripts/cder/daf/index.cf m?event=overview.process\&applno=011525

26. Giraudeau C, Moussaron A, Stallivieri A, Mordon S, Frochot C. Indocyanine green: photosensitizer or chromophore? Still a Debate. Curr. Med. Chem. 21(16), 1871-1897 (2014).

-. Review discussing the use of indocyanine green for different treatments.

27. Reindl S, Penzkofer A, Gong S-H et al. Quantum yield of triplet formation for indocyanine green. J. Photochem. Photobiol. Chem. 105(1), 65-68 (1997).

28. Hopp M, Biffar R. Die ICG-gestütze photothermische therapie (PTT). ZMK29(9), 528-541 (2013).

29. Urbanska K, Romanowska-Dixon B, Matuszak Z, Oszajca J, Nowak-Sliwinska P, Stochel G. Indocyanine green as a prospective sensitizer for photodynamic therapy of melanomas. Acta Biochim. Pol. 49(2), 387-391 (2002).

30. Engelschalk M. Photodynamische therapie oder photothermale therapie. Laser J. 16(2), 12-14 (2013).

31. Beltes C, Economides N, Sakkas H, Papadopoulou C, Lambrianidis T. Evaluation of antimicrobial photodynamic therapy using indocyanine green and near-infrared diode laser against Enterococcus faecalis in infected human root canals. Photomed. Laser Surg. 35(5), 264-269 (2017).

32. Afkhami F, Akbari S, Chiniforush N. Entrococcus faecalis elimination in root canals using silver nanoparticles, photodynamic therapy, diode laser, or laser-activated nanoparticles: an in vitro study. J. Endod. 43(2), 279-282 (2017).

33. Beytollahi L, Pourhajibagher M, Chiniforush $\mathrm{N}$ et al. The efficacy of photodynamic and photothermal therapy on biofilm formation of Streptococcus mutans: an in vitro study. Photodiagnosis Photodyn. Ther. 17, 56-60 (2017).

34. Pourhajibagher M, Chiniforush N, Parker S et al. Evaluation of antimicrobial photodynamic therapy with indocyanine green and curcumin on human gingival fibroblast cells: an in vitro photocytotoxicity investigation. Photodiagnosis Photodyn. Ther. 15, 13-18 (2016). 
35. Bolhari B, Pourhajibagher M, Bazarjani F et al. Ex vivo assessment of synergic effect of chlorhexidine for enhancing antimicrobial photodynamic therapy efficiency on expression patterns of biofilm-associated genes of Enterococcus faecalis. Photodiagnosis Photodyn. Ther. 22, 227-232 (2018).

36. Akbari T, Pourhajibagher M, Hosseini F et al. The effect of indocyanine green loaded on a novel nano-graphene oxide for high performance of photodynamic therapy against Enterococcus faecalis. Photodiagnosis Photodyn. Ther. 20, 148-153 (2017).

37. Pourhajibagher M, Chiniforush N, Ghorbanzadeh R, Bahador A. Photo-activated disinfection based on indocyanine green against cell viability and biofilm formation of Porphyromonas gingivalis. Photodiagnosis Photodyn. Ther. 17, 61-64 (2017).

38. Omar GS, Wilson M, Nair SP. Lethal photosensitization of wound-associated microbes using indocyanine green and near-infrared light. BMC Microbiol. 8, 111 (2008).

39. Al-Ahmad A, Bucher M, Anderson AC et al. Antimicrobial photoinactivation using visible light plus water-filtered infrared-A (VIS + wIRA) alters in situ oral biofilms. PLoS ONE 10(7), e0132107 (2015).

40. Piazena H, Kelleher DK. Effects of infrared-A irradiation on skin: discrepancies in published data highlight the need for an exact consideration of physical and photobiological laws and appropriate experimental settings. Photochem. Photobiol. 86(3), 687-705 (2010).

-• One of the first articles clearly showing the positive effects of IRA on the skin and stressing the need for an appropriate setting.

41. Vaupel P, Piazena H, Müller W, Notter M. Biophysical and photobiological basics of water-filtered infrared-A hyperthermia of superficial tumors. Int. J. Hyperthermia. 35(1), 26-36 (2018).

42. Piazena H, Meffert H, Uebelhack R. Spectral remittance and transmittance of visible and infrared-A radiation in human skin-comparison between in vivo measurements and model calculations. Photochem. Photobiol. 93(6), 1449-1461 (2017).

43. Jones D, Pell PA, Sneath PHA. Maintenance of bacteria on glass beads at $-60^{\circ} \mathrm{C}$ to- $76^{\circ} \mathrm{C}$. In: Maintenance of Microorganisms: A Manual of Laboratory Methods. Kirsop BE, Snell JJS (Eds). Academic Press, London, UK, 35-40 (1984).

44. Karygianni L, Follo M, Hellwig E et al. Microscope-based imaging platform for large-scale analysis of oral biofilms. Appl. Environ. Microbiol. 78(24), 8703-8711 (2012).

45. Al-Ahmad A, Follo M, Selzer A-C, Hellwig E, Hannig M, Hannig C. Bacterial colonization of enamel in situ investigated using fluorescence in situ hybridization. J. Med. Microbiol. 58(10), 1359-1366 (2009).

46. Al-Ahmad A, Wiedmann-Al-Ahmad M, Fackler A et al. In vivo study of the initial bacterial adhesion on different implant materials. Arch. Oral Biol. 58(9), 1139-1147 (2013).

47. Tawakoli PN, Al-Ahmad A, Hoth-Hannig W, Hannig M, Hannig C. Comparison of different live/dead stainings for detection and quantification of adherent microorganisms in the initial oral biofilm. Clin. Oral Investig. 17(3), 841-850 (2013).

48. Al-Ahmad A, Wunder A, Auschill TM et al. The in vivo dynamics of Streptococcus spp., Actinomyces naeslundii, Fusobacterium nucleatum and Veillonella spp. in dental plaque biofilm as analysed by five-colour multiplex fluorescence in situ hybridization. J. Med. Microbiol. 56(5), 681-687 (2007).

49. Landsman ML, Kwant G, Mook GA, Zijlstra WG. Light-absorbing properties, stability, and spectral stabilization of indocyanine green. J. Appl. Physiol. 40(4), 575-583 (1976).

50. Fox IJ, Brooker LGS, Heseltime DW, Wood EH. A new dye for continous recording of dilution curves in whole blood independent of variations in blood oxygen saturation. Circulation 14, 937-938 (1956).

51. Cherrick GR, Stein SW, Leevy CM, Davidson CS. Indocyanine green: observations on its physical properties, plasma decay, and hepatic extraction. J. Clin. Invest. 39(4), 592-600 (1960).

52. Benya R, Quintana J, Brundage B. Adverse reactions to indocyanine green: a case report and a review of the literature. Cathet. Cardiovasc. Diagn. 17(4), 231-233 (1989).

53. Porcu EP, Salis A, Gavini E, Rassu G, Maestri M, Giunchedi P. Indocyanine green delivery systems for tumour detection and treatments. Biotechnol. Adv. 34(5), 768-789 (2016).

-. Review reporting the use of indocynine green in the oncological field.

54. Bach G. Langzeitbehandlung periimplantärer läsionen in der alterszahnheilkunde. Laser J. 2013(1), 35-37 (2013).

55. Fekrazad R, Khoei F, Hakimiha N, Bahador A. Photoelimination of Streptococcus mutans with two methods of photodynamic and photothermal therapy. Photodiagnosis Photodyn. Ther. 10(4), 626-631 (2013).

56. Engel E, Schraml R, Maisch T et al. Light-induced decomposition of indocyanine green. Invest. Ophthalmol. Vis. Sci. 49(5), 1777-1783 (2008).

57. Al-Ahmad A, Walankiewicz A, Hellwig E et al. Photoinactivation using visible light plus water-filtered infrared-A (vis+wIRA) and chlorine e6 (Ce6) eradicates planktonic periodontal pathogens and subgingival biofilms. Front. Microbiol. 7, 1900 (2016).

58. Jung T, Grune T. Experimental basis for discriminating between thermal and athermal effects of water-filtered infrared A irradiation: thermal and athermal wIRA effects. Ann. N. Y. Acad. Sci. 1259(1), 33-38 (2012).

59. Rolim JPML, De-Melo MAS, Guedes SF et al. The antimicrobial activity of photodynamic therapy against Streptococcus mutans using different photosensitizers. J. Photochem. Photobiol. B. 106, 40-46 (2012).

60. Akca O, Melischek M, Scheck T et al. Postoperative pain and subcutaneous oxygen tension. Lancet 354(9172), 41-42 (1999). 
61. Hürlimann AF, Hänggi G, Panizzon RG. Photodynamic therapy of superficial basal cell carcinomas using topical 5-aminolevulinic acid in a nanocolloid lotion. Dermatology 197(3), 248-254 (1998).

62. Schumann H, Calow T, Weckesser S, Müller ML, Hoffmann G. Water-filtered infrared A for the treatment of chronic venous stasis ulcers of the lower legs at home: a randomized controlled blinded study: wIRA for chronic venous stasis ulcers. Br. J. Dermatol. 165(3), 541-551 (2011).

63. Von Felbert V, Hoffmann G, Hoff-Lesch S et al. Photodynamic therapy of multiple actinic keratoses: reduced pain through use of visible light plus water-filtered infrared A compared with light from light-emitting diodes: PDT of multiple AKs: reduced pain through VIS + wIRA. Br. J. Dermatol. 163(3), 607-615 (2010).

- One of the first articles to clearly show the pain reducing effects of visible light andwater-filtered infrared A radiation compared with other widely used light sources.

64. Jung T, Höhn A, Piazena H, Grune T. Effects of water-filtered infrared A irradiation on human fibroblasts. Free Radic. Biol. Med. 48(1), 153-160 (2010).

65. Giehl KA, Kriz M, Grahovac M, Ruzicka T, Berking C. A controlled trial of photodynamic therapy of actinic keratosis comparing different red light sources. Eur. J. Dermatol. 24(3), 335-341 (2014).

66. Kranz S, Huebsch M, Guellmar A, Voelpel A, Tonndorf-Martini S, Sigusch BW. Antibacterial photodynamic treatment of periodontopathogenic bacteria with indocyanine green and near-infrared laser light enhanced by Trolox ${ }^{\text {TM }}$. Lasers Surg. Med. 47(4), 350-360 (2015).

67. Azizi A, Shademan S, Rezai M, Rahimi A, Lawaf S. Effect of photodynamic therapy with two photosensitizers on Streptococcus mutants: in vitro study. Photodiagnosis Photodyn. Ther. 16, 66-71 (2016).

68. Topaloglu N, Guney M, Aysan N, Gulsoy M, Yuksel S. The role of reactive oxygen species in the antibacterial photodynamic treatment: photoinactivation vs proliferation. Lett. Appl. Microbiol. 62(3), 230-236 (2016).

69. Topaloglu N, Gulsoy M, Yuksel S. Antimicrobial photodynamic therapy of resistant bacterial strains by indocyanine green and 809-nm diode laser. Photomed. Laser Surg. 31(4), 155-162 (2013).

- An article demonstrating the antimicrobial effects of indocynine green against both Gram-negative and Gram-positive bacteria.

70. Meisel P, Kocher T. Photodynamische therapie in der parodontologie viele studien, wenig evidenz. gemeinsame wissenschaftliche mitteilung der deutschen gesellschaft für parodontologie und der gesellschaft für zahn- mund- und kieferheilkunde. Parodontologie 48, 591-599 (2015).

71. Srikanth K, Chandra RV, Reddy AA, Reddy BH, Reddy C, Naveen A. Effect of a single session of antimicrobial photodynamic therapy using indocyanine green in the treatment of chronic periodontitis: a randomized controlled pilot trial. Quintessence Int. 46(5), 391-400 (2015).

72. Saffarpour A, Fekrazad R, Heibati $\mathrm{M}$ et al. Bactericidal effect of erbium-doped yttrium aluminum garnet laser and photodynamic therapy on aggregatibacter actinomycetemcomitans biofilm on implant surface. Int. J. Oral Maxillofac. Implants. 31(3), e71-e78 (2016).

73. Chambless JD, Hunt SM, Stewart PS. A three-dimensional computer model of four hypothetical mechanisms protecting biofilms from antimicrobials. Appl. Environ. Microbiol. 72(3), 2005-2013 (2006).

74. Teles FR, Teles RP, Sachdeo A et al. Comparison of microbial changes in early redeveloping biofilms on natural teeth and dentures. $J$. Periodontol. 83(9), 1139-1148 (2012).

75. de Sant'anna GR, Dos Santos EAP, Soares LES et al. Dental enamel irradiated with infrared diode laser and photoabsorbing cream: part 1 - FT-Raman Study. Photomed. Laser Surg. 27(3), 499-507 (2009).

76. McNally KM, Gillings BRD, Dawes JM. Dye-assisted diode laser ablation of carious enamel and dentine. Aust. Dent. J. 44(3), 169-175 (1999).

77. Pourhajibagher M, Chiniforush N, Shahabi S, Ghorbanzadeh R, Bahador A. Sub-lethal doses of photodynamic therapy affect biofilm formation ability and metabolic activity of Enterococcus faecalis. Photodiagnosis Photodyn. Ther. 15, 159-166 (2016).

78. Chiniforush N, Pourhajibagher M, Shahabi S, Kosarieh E, Bahador A. Can antimicrobial photodynamic therapy (aPDT) enhance the endodontic treatment? J. Lasers Med. Sci. 7(2), 76-85 (2016).

79. Bashkatov AN, Genina EA, Kochubey VI, Tuchin VV. Optical properties of human skin, subcutaneous and mucous tissues in the wavelength range from 400 to $2000 \mathrm{~nm}$. J. Phys. Appl. Phys. 38(15), 2543-2555 (2005). 
